\title{
High clarity poly(caprolactone diol)-based polyurethane adhesives for polycarbonate lamination: effect of isocyanate and chain-extender
}

\author{
S. McCreath ${ }^{\mathrm{a}}$, P. Boinard ${ }^{\mathrm{b}}$, E. Boinard ${ }^{\mathrm{b}}$, P. Gritter ${ }^{\mathrm{b}}$, J. J. Liggat ${ }^{\mathrm{a}^{*}}$ \\ aWestCHEM, Department of Pure and Applied Chemistry, University of Strathclyde, \\ Glasgow, Scotland
}

${ }^{b}$ Block 7, Vale of Leven Industrial Estate, Dumbarton, Dunbartonshire, Scotland

\begin{abstract}
The development of a high clarity polyurethane adhesive from a crystalline soft-phase capable of bonding untreated and ethanolamine surfaced-treated polycarbonate is described. A series of polyurethanes were prepared, based on poly(caprolactone diol), selected as the soft-phase as its ester-functionalised backbone structure will assist the adhesive performance. A high crystallinity soft-phase, however, will have an adverse effect on the adhesive's clarity. However, through careful design of the hard-phase architecture, it is possible to address this issue. Eight formulations were synthesised each with a subtly different hard-phase architecture, created using a combination of methylene diphenyl diisocyanate or isophorone diisocyanate with trimethylol propane only or by including the chain-extenders 2,2-diethyl1,3-propane diol, 1,3-butane diol and 1,2-propane diol. DSC and FTIR data show that having trimethylol propane alone is not sufficient in disrupting soft-phase crystallisation in the methylene diphenyl diisocyanate formulations, and that for total removal of soft-phase crystallisation a diol chain-extender is required to promote phase mixing within the microphase structure. This reduces peel strengths but values remain above $3 \mathrm{~N} \mathrm{~mm}^{-1}$ on both untreated and ethanolamine treated polycarbonate after 18 months. More importantly, the change to the morphology markedly improves clarity. In contrast, isophorone diisocyanate systems show poor phase mixing even in the presence of the chain-extenders and, although offering good peel strengths, have low clarity.
\end{abstract}

\section{KEYWORDS}

Polyurethane; adhesive; morphology; lamination; clarity

*CORRESPONDING AUTHOR FOOTNOTE. Ph: +44 (0)1415484351 email: j.j.liggat@strath.ac.uk 


\subsection{Introduction}

Developing a fit-for-purpose adhesive is challenging as it requires selection of the correct polymer type for the application of choice. ${ }^{1}$ Once the correct type of polymer has been selected, a rational design approach is required when selecting the specific components used in the formulation as these will dictate the post-cure morphology and therefore the adhesive properties. This design, selection and formulation process is essential in obtaining good compatibility with the substrate and therefore to obtaining a fit-for-purpose adhesive. Moisture-cured polyurethane-urea (MCPU-U) based polymers are a commonly encountered type of adhesive and coating as their properties can be tailored to meet a wide variety of applications. $^{2,3}$ The flexibility of these materials allows for both solvent-borne and bulk systems to be synthesised, leading to a large number of possible applications. ${ }^{4,5}$ Bulk systems are beginning to replace solvent-borne systems due to the environmental implications of the solvents used and the costly solvent-recovery processes. Bulk systems are formed by successive urethane reactions to form isocyanate end-capped polyurethane prepolymers (figure 1). The most frequently encountered types of prepolymer adhesive are low viscosity liquids or reactive hot melts. Low viscosity liquid type prepolymer adhesives are commonly used in applications such as textile bonding as the adhesive can penetrate the substrate, whereas, reactive hot melt adhesives are used in wood bonding where rapid strength development is required. ${ }^{6}$
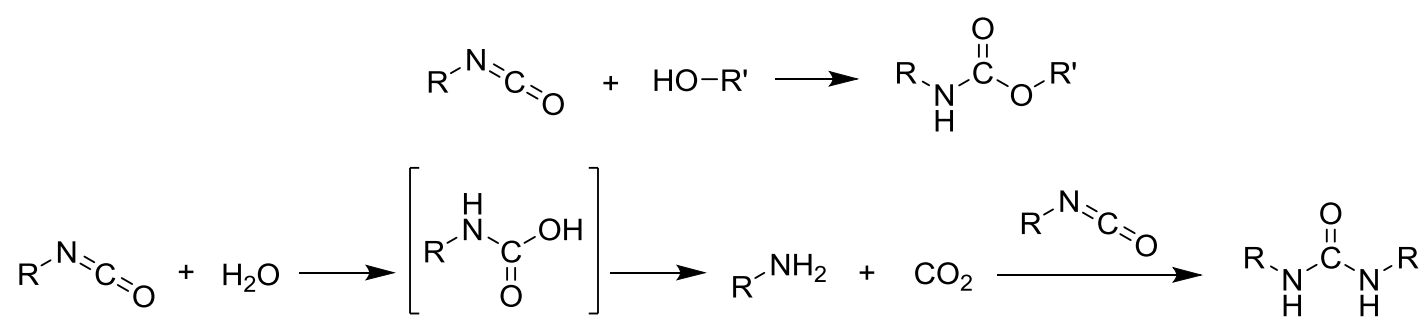

Figure 1: Most significant reactions in moisture-cured PU-U adhesive chemistry. [1] shows reaction of an isocyanate with a hydroxyl in forming a urethane linkage. [2] displays urea formation involving two isocyanate groups and water via a carbamic acid intermediate.

Moisture-cured PU-Us display impressive mechanical properties due to the biphasic morphology encountered within their microstructure..$^{7-9}$ An inherent insolubility between the two phases within the block copolymer leads to this biphasic morphology. ${ }^{10}$ For moisture- 
cured MCPU-Us, the biphasic morphology consists of a hard-segment and a soft-phase. The soft-phase is normally a polyether or polyester which possesses a low temperature glass transition, making it responsible for the flexibility and softness of the matrix. These properties can be adjusted via careful selection of the molecular weight, functionality and structure of the soft-phase. ${ }^{11,12}$ The hard-phase of the copolymer is responsible for the cohesive strength within the MCPU-U matrix and is constructed using diisocyanates and chain-extenders. The properties of the hard-phase can be modified by the hard-segment content, diisocyanate, chain-extender and curing conditions. ${ }^{11,13-15}$

MCPU-Us are commonly obtained by application of a polyurethane (PU) prepolymer which moisture cures via diffusion of water from the atmosphere. As moisture diffuses, nucleophilic attack of isocyanate groups by water occurs producing an amine and carbon dioxide. ${ }^{16}$ Reaction of these amine groups with a further isocyanate groups leads to the formation of urea linkages yielding the final MCPU-U material (figure 1) ${ }^{17}$ In coating applications, moisture diffusion occurs initially at the adhesive - air interface. As the coating beings to cure a "skin" forms at the interface, with this process altering the rate of further moisture diffusion to the bulk. The rate at which full cure is obtained will be determined by the rate of diffusion through the cured interface and the thickness of coating layer (coupled with other factors such as cure temperature, catalyst etc.). ${ }^{3}$ The rate of moisture diffusion into the coating will also be influenced by the substrate material. Substrates that contain moisture or through which moisture can permeate will cure faster than impermeable substrates. The moisture permeability of the substrate becomes more of an issue for lamination processes. Lamination removes the adhesive - air interface making the only routes for moisture diffusion to the adhesive through either the substrate or the laminate edge. Moisture diffusion into the adhesive and subsequent moisture cure will determine the final properties of the MCPU-U matrix. The effect of cross-link density on moisture diffusion and hence cure and adhesive strength were noted by Shih et al. who describe polyurethane reactive hot-melt adhesives from isocyanate-capped prepolymers prepared from polyester and/or polyether glycols and a diisocyanate monomers or polyisocyanate with MDI as the main ingredient ${ }^{18}$. The effects of $\mathrm{NCO} / \mathrm{OH}$ molar ratio on the morphology and physical properties of PUR were investigated by attenuated total reflectance Fourier transform infrared spectroscopy (ATR-FTIR), differential scanning calorimetry (DSC) and a universal testing machine. The results showed that their formulations had a high degree of microphase separation and the hydrogen-bonded urea signal increases significantly under the higher NCO 
content. Whilst the prepolymers with highest crystalline content showed the best green strength, the phase-separation would compromise clarity. Recently, Lei, Zhou et al. produced a silane-terminated polyurethane modified by the silane end-capper anilinomethyltriethoxysilane, which could be moisture-cured at room temperature without releasing $\mathrm{CO}_{2}$. Although not commenting specifically on clarity they note that their MDIpoly(propylene glycol) formulations showed no crystallinity in either hard or soft blocks ${ }^{19}$.<smiles>CC(O)CO</smiles>

(a)<smiles>CCC(CC)(CO)CO</smiles>

(b)<smiles>CC(O)CCO</smiles>

(c)<smiles>CCC(CO)(CO)CO</smiles>

(d)

Figure 2: Structures of the chain-extenders used during synthesis. (a) 1,2-propane diol, (b) 2,2-diethyl-1,3-propane diol, (c) 1,3-butane diol and (d) trimethylol propane.

Within the present study, MCPU-U adhesives based on methylene diphenyl diisocyanate (MDI), isophorone diisocyanate (IPDI) and poly(caprolactone diol) (PCD) were investigated. Work was carried out to determine the effect that altering the hard-phase architecture has on the adhesives' clarity, morphology and adhesion. MDI was selected as the hard-phase due to the high compatibility with polycarbonate (PC) which results from their similar aromatic structures. IPDI was selected as the hard-phase due its asymmetric structure and good UV stability. PCD was selected as the soft-phase because having ester groups within the softphase will help promote adhesion with the polycarbonate substrate. Four PU prepolymer adhesives were synthesised using MDI and PCD, one formulation contained the triol chainextender trimethylol propane (TMP) only and the other three formulations contained TMP with either 2,2-diethyl-1,3-propane diol (DEPD), 1,3-butane diol (BD) or 1,2-propane diol (PD) (chain extender structures shown figure 2). Similarly, four PU prepolymer adhesives were synthesised using IPDI and PCD, one formulation contained the triol chain-extender trimethylol propane (TMP) only and the other three formulations contained TMP with either 2,2-diethyl-1,3-propane diol (DEPD), 1,3-butane diol (BD) or 1,2-propane diol (PD) (chainextender structures shown in figure 2). Characterisation of each cured MCPU-U was 
performed by ATR-FTIR, and DSC. The peel strength of each adhesive with untreated and ethanolamine surface treated polycarbonate was measured by $180^{\circ} \mathrm{T}$-peel testing. The clarity of the adhesive within the PC laminate was investigated using a light diffusion technique.

\subsection{Experimental}

\subsection{Materials}

The following materials were purchased from Sigma-Aldrich ${ }^{\circledR}$ and used as received: MDI, IPDI, dibutyltin dilaurate (DBTDL), triethylamine (TEA), isopropyl alcohol (IPA) and ethanolamine (EA). TMP, DEPD, BD, PD all Sigma-Aldrich ${ }^{\circledR}$, were dried at $80^{\circ} \mathrm{C}$ under vacuum prior to use. 2000 molecular weight PCD was provided by Perstorp $\operatorname{Ltd}^{\circledR}$ and was dried at $80^{\circ} \mathrm{C}$ under vacuum prior to use. $175 \mu \mathrm{m}$ thick bisphenol-A polycarbonate (PC) film was supplied by Sabic.

\subsection{Prepolymer synthesis}

The reaction kettle was equipped with a nitrogen inlet, nitrogen outlet, over-head mechanical stirrer, K-type thermocouple and a reactant addition inlet. The PU prepolymer synthesis was carried out in two-steps as shown in schemes 1 and 2. In step one a mixture of PCD with 10 mole\% of triol chain-extender TMP was added to the reaction kettle (calculated from the number of moles of $\mathrm{OH}$ in $\mathrm{PCD}$ ) and allowed to equilibrate between $85^{\circ} \mathrm{C}-95^{\circ} \mathrm{C}$ for 30 minutes with constant stirring. Next MDI or IPDI was added at a 2.2:1.0 stoichiometric ratio of $\mathrm{NCO}: \mathrm{OH}$ in $1 \mathrm{ml}$ portions to ensure the temperature did not exceed $95^{\circ} \mathrm{C}$. Once all diisocyanate was added, the reaction was left to stir for 3 hours for MDI or 5 hours for the less reactive IPDI. The TMP-only formulation was complete at this stage and transferred to an aluminium tube which was stored at $5^{\circ} \mathrm{C}$ under vacuum until application. For step two, the prepolymer was chain-extended with one of the low-molecular weight diols. The $\mathrm{NCO}: \mathrm{OH}$ addition ratio of chain-extender was 2.2:1.0 and was based on the calculated free isocyanate content remaining after step one. Following addition of the chain-extender, the reaction was left to stir between $85^{\circ} \mathrm{C}$ and $95^{\circ} \mathrm{C}$ for 5 hours (MDI) or 17 hours (IPDI). Next the catalyst was added at $0.1 \%$ of the total batch weight with $0.05 \%$ TEA and $0.05 \%$ DBTDL being the catalyst combination. The PU prepolymer was then transferred to an aluminium tube and stored under vacuum at $5^{\circ} \mathrm{C}$ until application. Formulations were used within one week of synthesis. 


\subsection{PC surface treatment}

Each PC film was surface treated using a 70:30 treatment solution consisting of IPA:EA and was based on a study by Li and Wilkes. ${ }^{20}$ The treatment solution was applied by wiping over the film's surface for two minutes, followed by a one minute rest period to allow solvent evaporation and then placed within a $120^{\circ} \mathrm{C}$ oven for two minutes. Once removed from the oven the surface treatment process was complete and the film was ready for adhesive application.

\subsection{Adhesive application}

Adhesive application was carried out using a heated gun-applicator into which the aluminium tube containing the formulation was inserted. Application temperatures were formulation dependent and varied between $160^{\circ} \mathrm{C}-180^{\circ} \mathrm{C}$. Two different laminate combinations were prepared consisting of $\mathrm{PC}$ to $\mathrm{PC}$ and $\mathrm{PC}(\mathrm{t})$ to $\mathrm{PC}(\mathrm{t})((\mathrm{t})$ denotes treated surface). The adhesive was applied to the bottom substrate prior to both plies passing through a set of steel nip rollers with a fixed gap to leave a $50 \mu \mathrm{m}$ adhesive thickness. Lamination was driven by a second set of rubber rollers which were set at $1 \mathrm{~m} \mathrm{~min}^{-1}$ with a clamping pressure of $20 \mathrm{psi}$. Following lamination each sample was cured at room temperature.

\subsection{Attenuated total reflectance Fourier transform infrared spectroscopy (ATR-FTIR)}

Analysis was carried out on Agilent Technologies 4500 Series Portable FTIR Spherical Diamond ATR. Each spectrum consisted of 128 scans with $8 \mathrm{~cm}^{-1}$ resolution with the sampling depth around $2 \mu \mathrm{m}$ at $1000 \mathrm{~cm}^{-1}$. Characterisation of each adhesive using ATRFTIR was obtained on 30 day $180^{\circ}$ T-peel samples. Analysis of each laminate was carried out at nine random positions along the sample length. These nine spectra were then averaged to determine the variation within the adhesive layer. All ATR-FTIR spectral averaging was carried out using LabCognition ${ }^{\circledR}$ Panorama and all spectra plotted using Originlab OriginPro ${ }^{\circledR}$ 9.0. Deconvolution of the $\mathrm{N}-\mathrm{H}$ and $\mathrm{C}=\mathrm{O}$ regions was performed using OriginPro ${ }^{\circledR} 9.0$ software using the Gaussian fitting function.

\subsection{Differential scanning calorimetry (DSC)}

All DSC experiments were carried out using a TA Q1000 differential scanning calorimeter. Analysis of MCPU-U samples typically involved 5-10 mg of sample within an aluminium pan. Experiments were performed under a nitrogen gas purge flow of $40 \mathrm{ml} \mathrm{min}^{-1}$ with cooling/heating rates of $10^{\circ} \mathrm{C} \mathrm{min}^{-1}$ and a cool-heat-cool-reheat procedure. Samples were initially cooled to $-90^{\circ} \mathrm{C}$ and heated to $150^{\circ} \mathrm{C}$ in order to remove any thermal history from the 
sample. Samples were then cooled to $-90^{\circ} \mathrm{C}$ and then heated to $300^{\circ} \mathrm{C}$. The initial scan is important as it represents the morphology as produced during the lamination process whilst the second scan provides more general insight into the morphology. To allow sample exposure to the purge gases, the lid of the aluminium pan was pierced prior to the experiment being carried out. All experimental data was analysed with TA's thermal analysis software and were plotted using OriginPro ${ }^{\circledR} 9.0$.

From the DSC data, crystallinity $\left(\mathrm{X}_{\mathrm{c}}\right)$ of the soft-phase PCD was calculated using equation 1:

$$
\mathrm{Xc}=\frac{\Delta \mathrm{Hm}}{\Delta \mathrm{H}^{\circ} \mathrm{m}} \times \mathrm{wt} \% \mathrm{sp} \quad \text { Equation } 1
$$

$\Delta \mathrm{H}_{\mathrm{m}}=$ soft-phase melting enthalpy measured by DSC, $\Delta \mathrm{H}^{\circ}{ }_{\mathrm{m}}=142 \mathrm{~J} \mathrm{~g}^{-1}$ is the melting enthalpy of completely crystalline PCD and wt $\% \mathrm{sp}=$ weight percent of soft-phase.

wt $\%$ sp was calculated using equation 2 :

$$
\text { wt } \% \text { sp }=100-w t \% h p
$$

Equation 2

$\mathrm{wt} \% \mathrm{hp}=$ weight percent of hard-phase.

Calculation of wt $\%$ hp was carried out using equation 3 :

$$
w t \% h p=\frac{R\left(M_{h p}\right)+(R-1) M_{c e}}{M_{s p}+R\left(M_{h p}\right)+(R-1) M_{c e}}
$$

Equation 3

$\mathrm{R}=$ stoichiometry of diisocyanate to polyol, $\mathrm{M}_{\mathrm{hp}}=$ mass of diisocyanate used in hard-phase, $\mathrm{M}_{\mathrm{ce}}=$ mass of chain-extender(s) used in hard-phase and $\mathrm{M}_{\mathrm{sp}}=$ number average molecular weight of PCD.

\section{$2.7180^{\circ}$ T-peel testing}

$180^{\circ}$ T-peel testing was carried out using an Instron 4301 equipped with a $1 \mathrm{kN}$ load cell. Sample width was fixed at $25 \mathrm{~mm}$, extension length was fixed at $150 \mathrm{~mm}$ and extension rate was fixed at $100 \mathrm{~mm} \mathrm{~min}^{-1}$. Samples were tested at three intervals following lamination, namely 1 week, 1 month and 18 months. Following 1 month of cure, the target peel strength was $3 \mathrm{~N} \mathrm{~mm}^{-1}$ with this value to be maintained over 18 months. Peel strength is calculated from the data between $50-150 \mathrm{~mm}$. When calculating the peel strength, the first $50 \mathrm{~mm}$ of the trace is not included as this is the region in which a stable crack is formed. Peel strength values are then calculated using equation 4 : 


$$
\mathrm{P}=\frac{\mathrm{L}}{\mathrm{W}}(1-\cos \theta)
$$

Equation 4

$\mathrm{P}=$ peel strength in $\mathrm{N} \mathrm{mm}^{-1}$,

$\mathrm{L}=$ load in $\mathrm{N}$,

$\mathrm{w}=$ sample width in $\mathrm{mm}$,

$\theta=$ peel angle.

As the peel angle used within this study was $180^{\circ}$ equation 1 reduces to equation 5 :

$$
\mathrm{P}=\frac{2 \mathrm{~L}}{\mathrm{~W}}
$$

Equation 5

The values obtained are the average of three sample replicates.

\subsection{Clarity determination}

The clarity of each MCPU-U was tested using a BYK Gardner ${ }^{\circledR}$ Haze-gard dual light diffusion technique. The clarity value quoted for each adhesive is an average value obtained from five test replicates. The test employed measures transmittance and deviation angle of the incident beam by the laminated material. Clarity data was analysed in accordance with ASTM D1003. Testing is performed by placing the laminate sample in the path of a narrow beam of incident light and as the incident beam passes through the material it will either pass through unimpeded or be diffusely scattered. Both these parts of the beam then enter into an integration sphere equipped with a photodetector. From this collected light, two quantities can be determined: the total strength of the light beam and the portion of the original beam that has been deviated by an angle of $>2.5^{\circ}$. Obtaining these two quantities allows for calculation of both the clarity, which is calculated from the wide angle diffuse component, and the luminous transmittance, which is the percentage of the incident beam that has been transmitted through the sample unimpeded. The target clarity value for each laminate is $<1.5 \%$. 
<smiles>O=C=Nc1ccc(Cc2ccc(N=C=O)cc2)cc1</smiles>

1<smiles>COC(=O)CCCCCC(C)C</smiles>

2

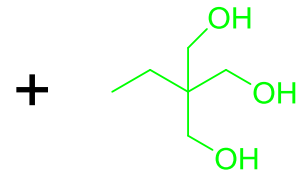

3

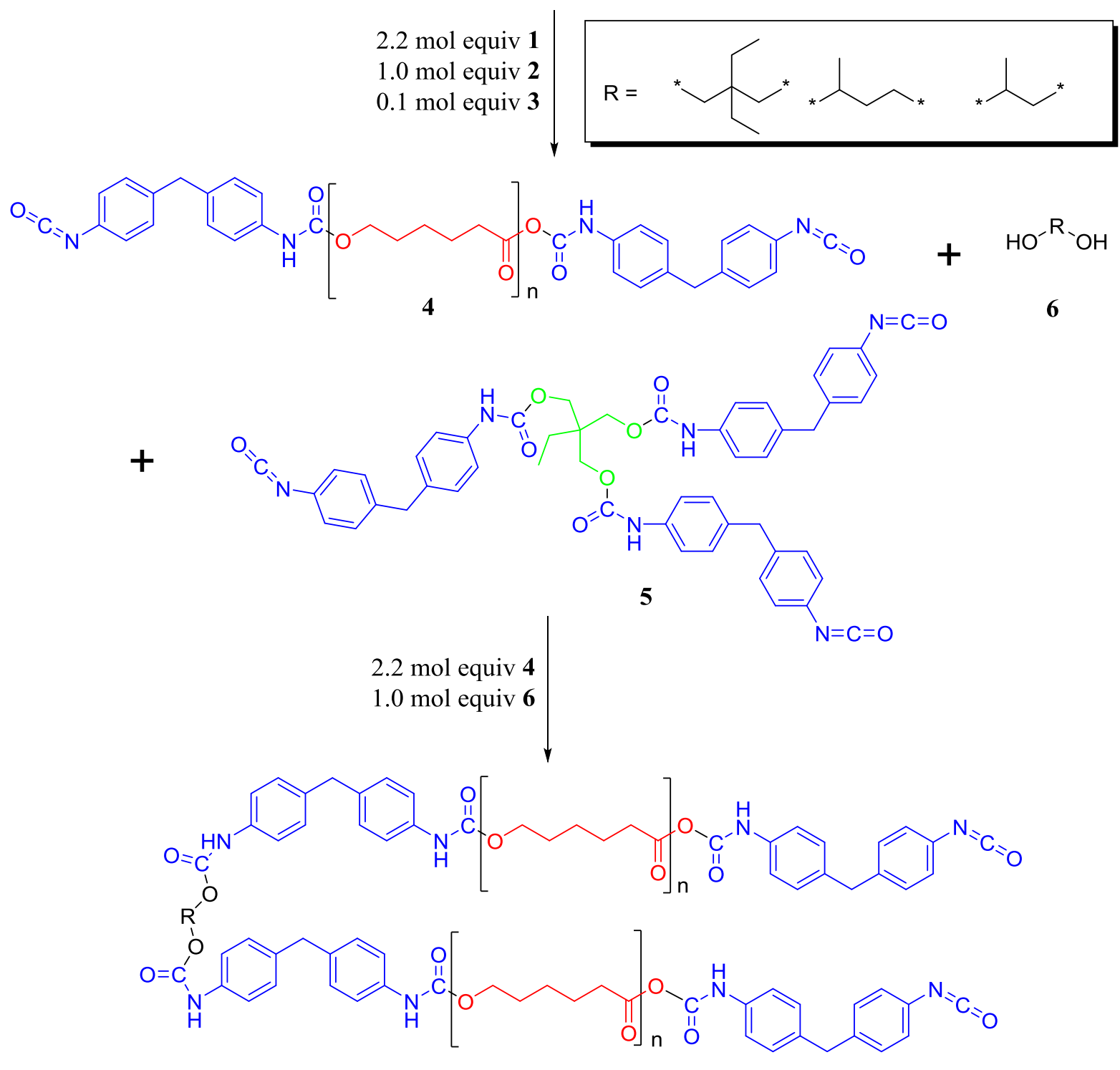

7

Scheme 1: General reaction scheme for the synthesis of MDI and PCD based prepolymer adhesives. $1=$ MDI, $2=$ PCD, $3=$ TMP, $4=$ isocyanate end capped prepolymer of PCD, 5 = isocyanate end capped prepolymer of TMP, $6=$ diol chainextender and $7=$ diol chain-extended prepolymer. 
<smiles>CC1(C)CC(N=C=O)CC(C)(CN=O)C1</smiles>

1<smiles>COC(C)C(C)C</smiles>

2

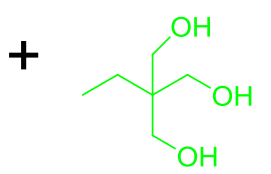

3<smiles>CC=NCC1(C)CC(NC(=O)OC(C)(C)C(C)OC(=O)NC2CC(C)(C)CC(C)(CN=C=O)C2)CC(C)(C)C1</smiles>

$2.2 \mathrm{~mol}$ equvi 1 1.0 mol equiv 2 0.1 mol equiv 3
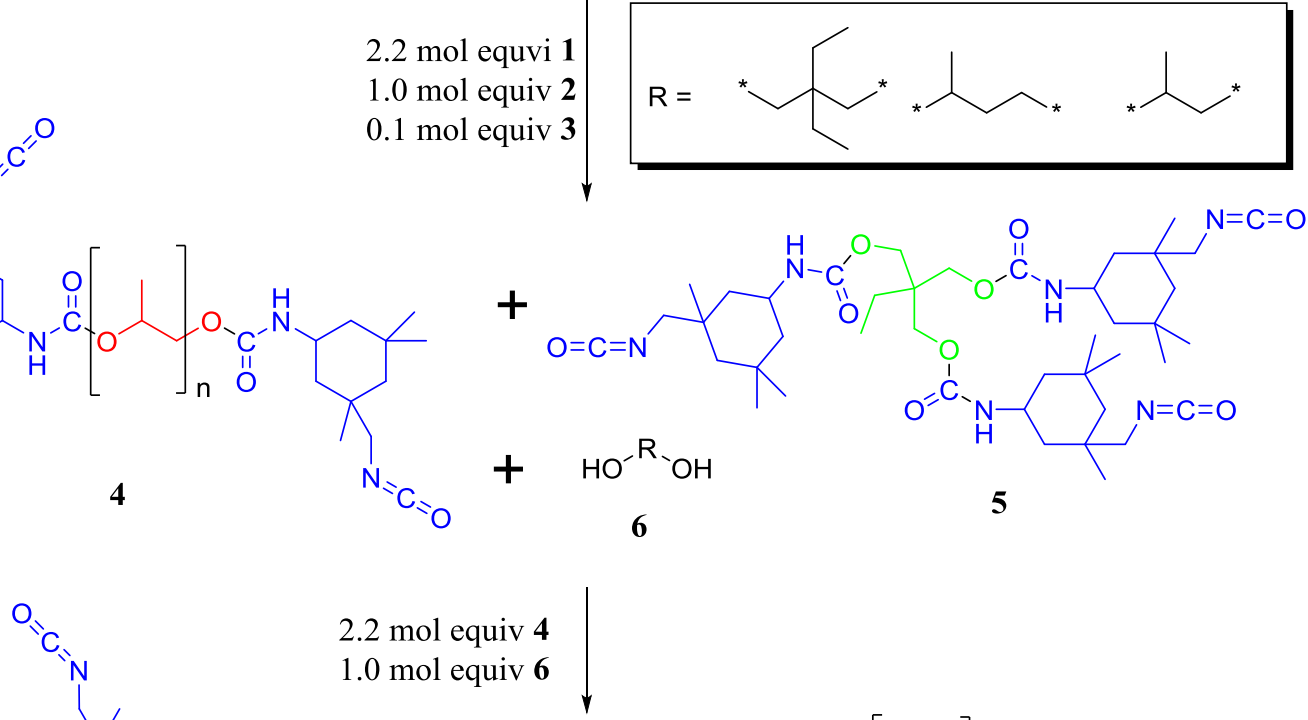
$1.0 \mathrm{~mol}$ equiv 6<smiles>[R]OC(=O)NCC1(C)CC(NC(=O)OCC)CC(C)(C)C1</smiles>

7

Scheme 2: General reaction scheme for the synthesis of IPDI and PCD based prepolymer adhesives. $1=$ IPDI, $2=$ PCD, $3=$ TMP, $4=$ isocyanate end capped prepolymer of PCD, 5 = isocyanate end capped prepolymer of TMP, $6=$ diol chainextender and $7=$ diol chain-extended prepolymer. 


\subsection{Results and discussion}

\subsection{Thermal analysis}

\subsubsection{DSC of MDI formulations}

DSC was used to explore the thermal characteristics of each formulation and to determine the effect that chain-extension has on the microphase structure. Shown within figure 3 are the DSC thermograms obtained during the first heating scan of each MCPU-U. A single glass transition was observed in each case from the soft-segment PCD. The position of the softsegment glass transition ( $\mathrm{T}_{\mathrm{gSs}}$ ) is shifted by a small but distinct increment to a higher temperature when a diol chain-extender is used. This shift occurs following the enforced changes to the packing arrangement due to the presence of each diol chain-extender within the hard-phase, resulting in greater phase mixing. DEPD, BD and PD have increased the phase to phase compatibility resulting in a higher degree of phase mixing and consequently removed soft-segment crystallisation.

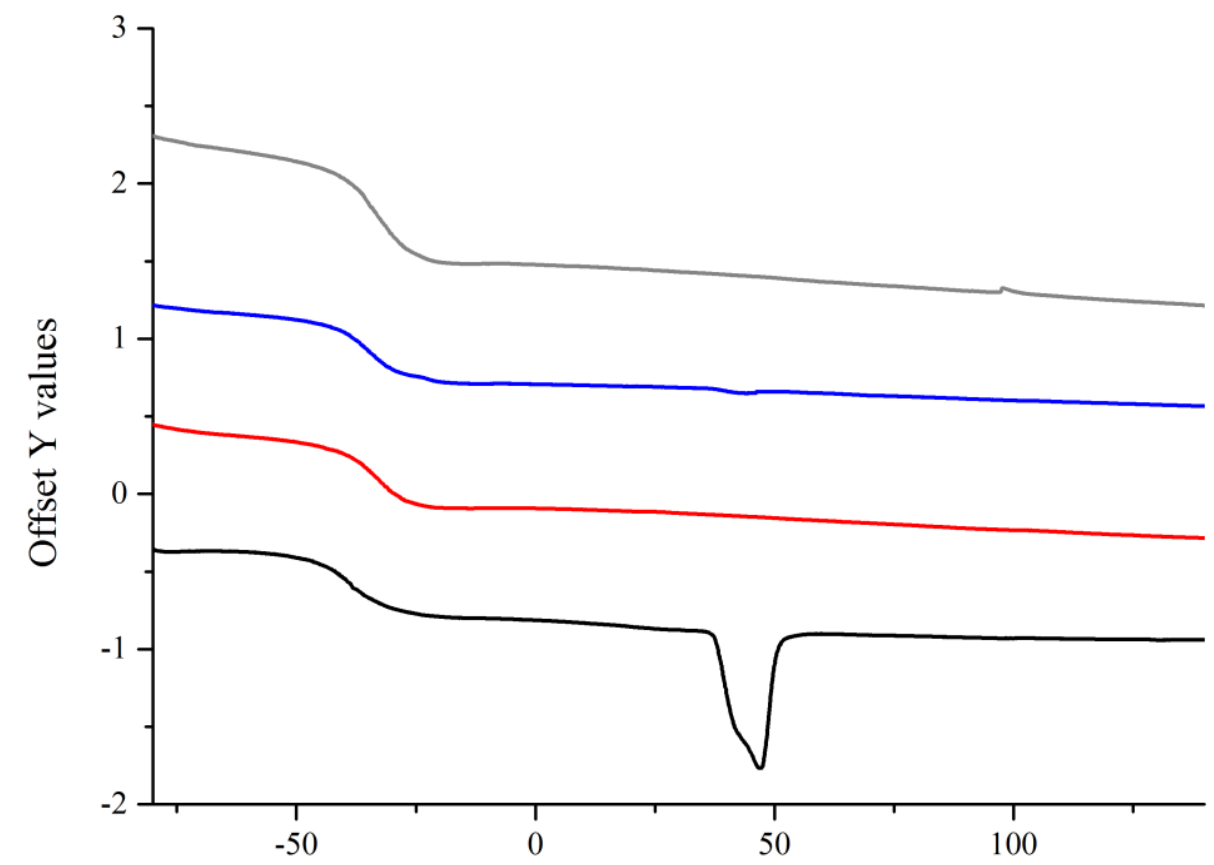

Exo up

Temperature $\left({ }^{\circ} \mathrm{C}\right)$

Figure 3: DSC thermograms of the first heating cycle of each MDI-based MCPU-U. [MDI-TMP-PCD in black, MDI-TMP-PCD-DEPD in red, MDI-TMP-PCD-BD in blue and MDI-TMP-PCD-PD in grey]. 
Chain-extender TMP does not completely remove PCD crystallinity, however, sufficient heterogeneities are introduced as the enthalpy of melting is reduced from $57 \mathrm{~J} \mathrm{~g}^{-1}$ to $8.6 \mathrm{~J} \mathrm{~g}^{-1}$ (see table 1). ${ }^{21}$ Due to phase mixing, Xc has decreased from $40.1 \%$ to $4.7 \%$ in MDI-TMPPCD. For each diol chain-extended formulations, the Xc value is zero as no soft-phase crystallisation is present. It would be expected that removing crystallisation from the softphase will lead to improved clarity, this will be discussed in section 3.3.

Table 1: DSC data for the first heating cycle of each MDI-based MCPU-U adhesive and PCD starting material.

\begin{tabular}{|c|c|c|c|c|c|c|}
\hline Formulation & HS wt\% & $\begin{array}{c}\mathbf{T}_{\mathrm{gSS}} \\
{ }^{\circ}{ }^{\circ} \mathrm{C}\end{array}$ & $\begin{array}{c}\mathbf{T}_{\mathrm{g} S S} \\
\text { Range } \\
{ }^{\circ} \mathrm{C}\end{array}$ & $\begin{array}{c}\mathbf{T}_{\mathbf{m}} \mathbf{S S} \\
{ }^{\circ} \mathbf{C}\end{array}$ & $\begin{array}{c}\Delta \mathbf{H}_{\mathrm{m}} \mathbf{s p} \\
/ \mathbf{J ~ g}^{-1}\end{array}$ & $\begin{array}{l}\mathrm{Xc} \\
/ \%\end{array}$ \\
\hline PCD & - & -64 & -67 to -58 & 50 & 57 & 40 \\
\hline MDI-TMP-PCD & 22.3 & -39 & -46 to -33 & 47 & 8.6 & 5 \\
\hline MDI-TMP-PCD-DEPD & 26.1 & -33 & -39 to -27 & - & - & 0 \\
\hline MDI-TMP-PCD-BD & 25.0 & -36 & -41 to -30 & - & - & 0 \\
\hline MDI-TMP-PCD-PD & 24.6 & -33 & -38 to -25 & - & - & 0 \\
\hline
\end{tabular}

$T_{g s S}=$ soft-segment glass transition temperature, $T_{m} s S=$ soft-segment peak melt temperature, $\Delta H_{m} s p=$ soft-phase melting enthalpy, $X c=$ soft-phase crystallinity

Data from the second heating cycles is shown within figure 4 and table 2. On the second heating cycle, the shift in the $\mathrm{T}_{\mathrm{gSs}}$ following diol chain-extension is more pronounced. When TMP is the sole chain-extender, the $\mathrm{T}_{\mathrm{gSs}}$ occurs at $-40^{\circ} \mathrm{C}$ which is the lowest value recorded. Following diol chain-extension a broadened glass transition is observed with each shifting to a higher temperature. This shift in the glass transition confirms that polymer chains within the soft-phase have become more conformationally constrained due to hard-to-soft-phase interactions. ${ }^{2}$ Crystallisation of the soft-segment is absent for MDI-TMP-PCD during the second heating cycle as the time frame of the experiment does not allow re-crystallisation to occur. 


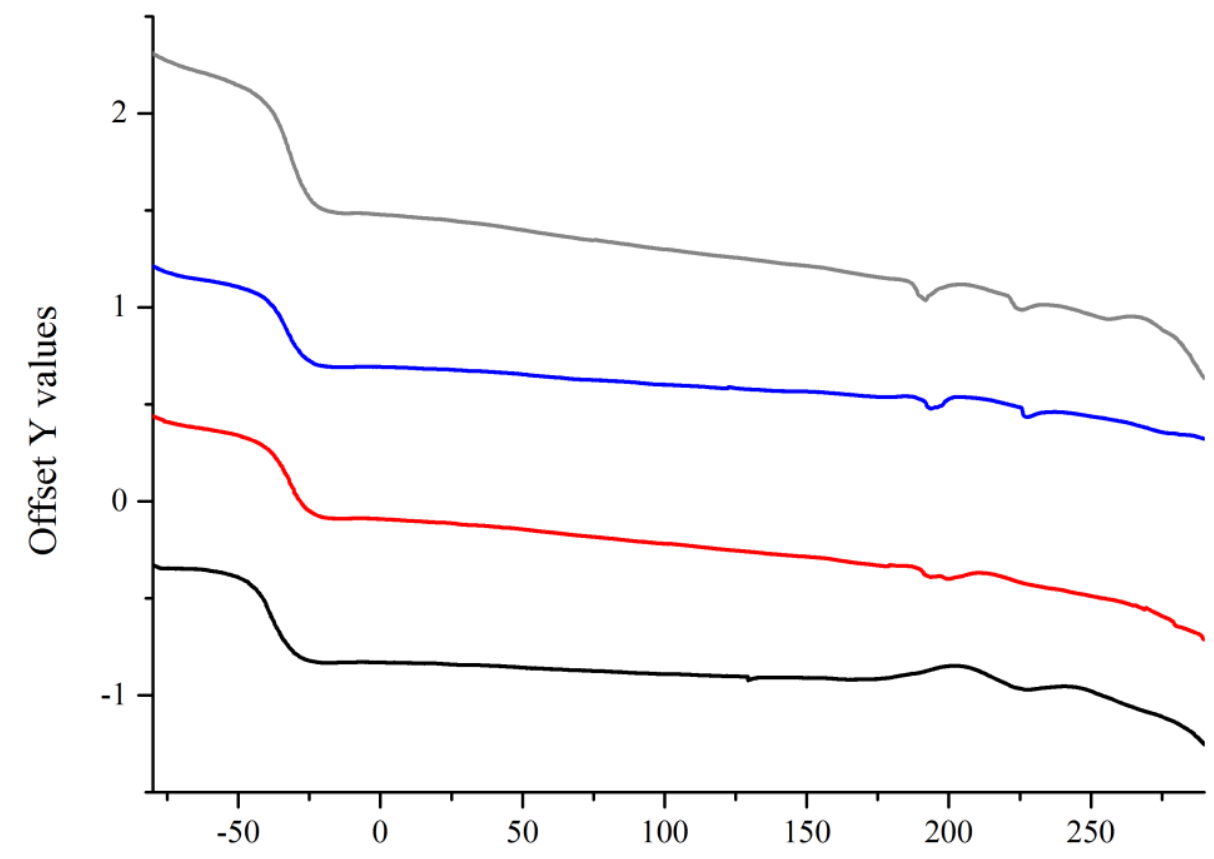

Exo up

Temperature $\left({ }^{\circ} \mathrm{C}\right)$

Figure 4: DSC thermograms of the second heating cycle of each MDI-based MCPU-U. [MDI-TMP-PCD in black, MDI-TMP-PCD-DEPD in red, MDI-TMP-PCD-BD in blue and MDI-TMP-PCD-PD in grey].

The effect that chain-extension has on the architecture of the hard-phase has been the subject of much debate. Ryan et al. discussed how precipitation of the chain-extender within the hard-phase has an effect on both the packing arrangement and overall segmented structure. ${ }^{9,17}$ Gisselfält et al. and Sànchez-Adsuar et al. reported that the chain-extenders length/structure has an influence on the microphase morphology, with short chain-extenders promoting ordered hard-segment packing along with phase separation. ${ }^{7,14}$ Within the Sànchez-Adsuar et al. study, ethylene glycol, 1,4-butane diol and 1,6-heaxane diol were used during synthesis. Their results confirmed that the shortest chain-extender, ethylene glycol resulted in the smallest shift of the $\mathrm{T}_{\mathrm{gSS}}$, whereas the longest chain-extender 1,6-hexane diol had the greatest shift in the $\mathrm{T}_{\mathrm{g}} \mathrm{ss}$. Within the current study, the chain-extender length is similar in each case as shown by the close grouping of $\mathrm{T}_{\mathrm{g} S \mathrm{~s}}$ values. Therefore, within the current study, both the diol chain-extenders length and structure can be expected to have a similar influence on the phase mixing observed. 
Such a relationship was observed by Gisselfält et al. where both the length and structure of the chain-extender was shown to influence the morphology. ${ }^{7}$ The results obtained within this study, where each diol chain-extender contains a least one side group (ethyl in DEPD and methyl for $\mathrm{BD}$ and $\mathrm{PD}$ ) is consistent with the observation of Gisselfält et al. in showing that phase mixing increases using chain-extenders of this type. By rationally designing changes to the hard-phase architecture using diol chain-extenders of this type, it is possible to influence the soft-phase and final morphology. It is believed that by introducing these chainextenders into the hard-phase, the order of the hydrogen bonding and $\pi-\pi$ stacking network is reduced. The result of reducing this hard-phase cohesion is an increase in the degree of phase mixing.

Table 2: DSC data for the second heating cycle of each MDI-based MCPU-U.

\begin{tabular}{|c|c|c|c|c|c|c|c|}
\hline Formulation & $\begin{array}{l}\mathbf{T}_{\mathrm{gSS}} \\
/{ }^{\circ} \mathrm{C}\end{array}$ & $\begin{array}{c}\mathbf{T}_{\mathbf{m}} \mathrm{hs1} \\
/^{\circ} \mathrm{C}\end{array}$ & $\begin{array}{c}\text { T } \mathbf{m h s 1} \\
\text { Enthalpy } \\
/ / \mathbf{J ~ g}^{-1}\end{array}$ & $\begin{array}{c}\mathbf{T}_{\mathrm{m}} \mathrm{hs} 2 \\
{ }^{\circ}{ }^{\circ} \mathrm{C}\end{array}$ & $\begin{array}{c}\text { T } \mathbf{m h s 2} \\
\text { Enthalpy } \\
/ \mathbf{J ~ g}^{-1}\end{array}$ & $\begin{array}{c}\mathbf{T}_{\mathrm{m}} \mathrm{hs} 3 \\
/^{\circ} \mathrm{C}\end{array}$ & $\begin{array}{c}\mathbf{T}_{\mathrm{m} h s 3} \\
\text { Enthalpy } \\
\text { / J } \mathbf{~ g}^{-1}\end{array}$ \\
\hline $\begin{array}{c}\text { MDI-TMP- } \\
\text { PCD }\end{array}$ & -40 & 178 & 0.8 & 221 & 1.0 & - & - \\
\hline $\begin{array}{l}\text { MDI-TMP- } \\
\text { PCD-DEPD }\end{array}$ & -31 & 177 & 0.2 & 193 & 0.7 & - & - \\
\hline $\begin{array}{c}\text { MDI-TMP- } \\
\text { PCD-BD }\end{array}$ & -33 & 193 & 0.6 & 227 & 0.4 & - & - \\
\hline $\begin{array}{c}\text { MDI-TMP- } \\
\text { PCD-PD }\end{array}$ & -32 & 192 & 0.6 & 223 & 0.4 & 255 & 0.3 \\
\hline
\end{tabular}
temperature.

Also, on the second heating cycle of each formulation, are observed high temperature melting endotherms between $170^{\circ} \mathrm{C}$ and $260^{\circ} \mathrm{C}$ (see figure 4). These endothermic processes correspond to the dissociation of the hydrogen bonded and $\pi-\pi$ stacked network within the hard-phase. ${ }^{2}$ With TMP being present within all formulations, the packing arrangement of the hard-phase will be affected as was shown by Petrović et al. ${ }^{13}$ Petrović et al. showed that TMP adds heterogeneity into the hard-phase which results in greater phase mixing. Further heterogeneity to the hard-phase architecture will be induced by the side groups of each diol chain-extender which also leads to greater phase mixing. The combination of both these disruptive factors has resulted in a complex melting profile with two or three melting 
endotherms. This result is consistent with the observations of Petrović et al., who observed complex melting endotherms and reported that having a TMP chain-extender concentration of $\geq 10 \%$ has a measurable influence on the hard-phase melting. ${ }^{13}$

When TMP is the only chain-extender, two endothermic processes are observed at $178^{\circ} \mathrm{C}$ and $221^{\circ} \mathrm{C}$. The total enthalpy of melting for these two processes is $1.8 \mathrm{~J} \mathrm{~g}^{-1}$. Compared to examples of linear MCPU-Us within the literature that contain similar hard-segment contents, this value is low. ${ }^{13,15}$ As the dissociation enthalpy is low it confirms that adding chemical cross-links to the hard-phase using TMP reduces the overall order as observed by Petrovic et al. ${ }^{13}$ Following diol chain-extension, the enthalpy values are further reduced which confirms that further heterogeneities have been added to the hard-phase architecture. ${ }^{7}$ Thermal transitions that occur below $200^{\circ} \mathrm{C}$ are believed to be due to hard-phase crystallites that are either small or of low order. As these domains are unordered/small they will dissociate at a lower melt temperature and therefore not aid the adhesive performance at high temperatures. Thermal transitions which appear above $200^{\circ} \mathrm{C}$ are the domains with more uniform packing and/or larger. These domains will be responsible for much of the cohesive strength within the microphase structure. There is also the potential that these high temperature endotherms are the relaxation of residual strain within the hard-phase. ${ }^{22}$ What influence this emerging hard-phase architecture has on the adhesion and clarity will be discussed in section 3.3.

\subsubsection{DSC of IPDI formulations}

Shown within figure 5 are the DSC thermograms obtained during the first heating scan for each IPDI-based MCPU-U. A single glass transition was observed in each case and the position of the transition has shifted by around $+20^{\circ} \mathrm{C}$ compared to the soft-phase PCD (see table 3). Irrespective of the chain-extender combination, the $\mathrm{T}_{\mathrm{gsp}}$ obtained occurs at a similar position with the main variation observed within the transitions range. This is in contrast to previous results where diol chain-extension resulted in a noticeable shift to the $\mathrm{T}_{\mathrm{gsp}}{ }^{2}$ From the data collected during the first heating cycle, it would appear that the final morphology of each MCPU-U is similar. 


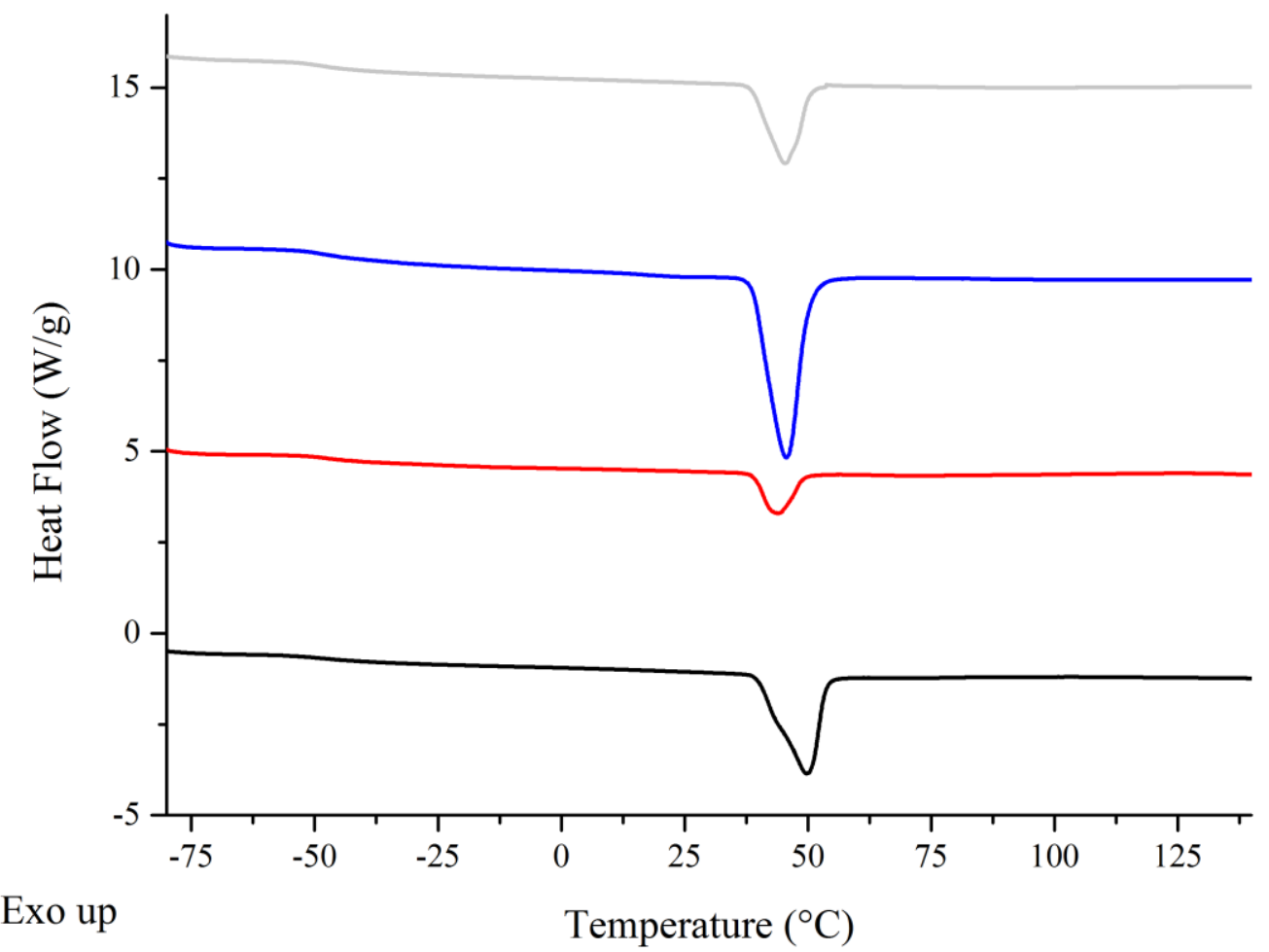

Figure 5: DSC thermograms of the first heating cycle of each IPDI-based MCPU-U. [IPDI-TMP-PCD in black, IPDI-TMP-PCD-DEPD in red, IPDI-TMP-PCD-BD in blue and IPDI-TMP-PCD-PD in grey].

As each MCPU-U is semi-crystalline in nature more information on the microphase morphology can be abstracted by analysing any change to the position or enthalpy of the softphase melting. Unreacted PCD has a melting point of $50^{\circ} \mathrm{C}$, the recorded enthalpy of fusion is $57 \mathrm{~J} \mathrm{~g}^{-1}$ and the $\mathrm{X}_{\mathrm{c}}$ value is $40.1 \%$. When TMP is the sole chain-extender, the position of melting remains consistent at $50^{\circ} \mathrm{C}$ but this is coupled with both a $52 \%$ reduction in the enthalpy of fusion value to $28 \mathrm{~J} \mathrm{~g}^{-1}$ and a greater than two-fold reduction in $\mathrm{X}_{\mathrm{c}}$. This suggests that soft-phase chains within formulation IPDI-TMP-PCD are more confirmation constrained than those of PCD due to interactions with the hard-phase. When diol chain-extenders are introduced, a reduction is observed in melting temperature, melting enthalpy and Xc. ${ }^{9,10,21}$ Of the chain-extenders, DEPD has the lowest melt temperature of $44^{\circ} \mathrm{C}$, lowest melting enthalpy of $9 \mathrm{~J} \mathrm{~g}^{-1}$ which is a reduction of $84 \%$ compared to PCD and lowest Xc value of $4.8 \%$. This 
displays that soft-phase purity has reduced following the addition of DEPD. Depreciation of both melt temperature and melting enthalpy confirms that changing the hard-phase architecture using slightly branched chain-extenders has an influence on the microphase morphology, resulting in greater phase mixing. As an Xc value could be calculated for each diol chain-extended formulation following cure (unlike the MDI-based formulations), it indicates that a hard-phase of IPDI is less miscible with PCD than a hard-phase of MDI.

Table 3: DSC data for the first heating cycle of each IPDI-based MCPU-U and PCD starting material.

\begin{tabular}{|c|c|c|c|c|c|c|}
\hline Formulation & $\begin{array}{c}\text { HS } \\
\text { wt\% }\end{array}$ & $\begin{array}{c}\mathbf{T}_{\mathrm{g}} \mathbf{S p} \\
{ }^{/{ }^{\circ} \mathrm{C}}\end{array}$ & $\begin{array}{c}\mathbf{T}_{\mathrm{g} S p} \\
\text { Range } \\
{ }^{\circ} \mathrm{C}\end{array}$ & $\begin{array}{c}\mathbf{T}_{\mathrm{m}} \mathbf{S p} \\
{ }^{/{ }^{\circ} \mathbf{C}}\end{array}$ & $\begin{array}{c}\Delta \mathbf{H}_{\mathrm{m}} \mathbf{s p} \\
/ \mathbf{J} \mathbf{g}^{-1}\end{array}$ & $\begin{array}{l}\mathrm{Xc} \\
/ \%\end{array}$ \\
\hline PCD & - & -64 & -67 to -58 & 50 & 57 & 40 \\
\hline IPDI-TMP-PCD & 20.4 & -46 & -50 to -40 & 50 & 28 & 16 \\
\hline IPDI-TMP-PCD-DEPD & 24.5 & -47 & -51 to -40 & 44 & 9 & 5 \\
\hline IPDI-TMP-PCD-BD & 23.2 & -46 & -53 to -36 & 46 & 23 & 12 \\
\hline IPDI-TMP-PCD-PD & 22.8 & -48 & -53 to -41 & 45 & 18 & 10 \\
\hline
\end{tabular}

On the second heating cycle a difference in the $T_{g} s p$ between diol chain-extended and the TMP-only formulation is observed (see figure 6 and table 4). In the TMP-only formulation, the $\mathrm{T}_{\mathrm{g}} \mathrm{sp}$ has shifted to a lower temperature of $-52^{\circ} \mathrm{C}$, indicating that the morphology has a greater degree of phase separation. For each diol chain-extended formulation, the $\mathrm{T}_{\mathrm{g}} \mathrm{sp}$ is unchanged relative to the first heating cycle, remaining between $-47^{\circ} \mathrm{C}$ and $-48^{\circ} \mathrm{C}$. The higher $\mathrm{T}_{\mathrm{gSp}}$ of the chain-extended formulations relative to the TMP-only formulation is consistent with the MDI-based formulations and suggests that urethane-based hard blocks formed during diol chain-extension mix better with PCD than urea-based hard blocks formed during cure. This argument is supported by the broader glass transition observed when DEPD, BD and PD are present within the formulation. Elevation and broadening of the glass transition are characteristic signs of phase mixing. ${ }^{3}$ 
Thus far it has been observed that any change to the hard-phase architecture results in a change to the overall microphase structure. This is evident in the hard-phase melting character of each formulation. In the second heating cycle of each MCPU-U, two high temperature melting endotherms are observed. Evident from inspection of each thermogram (see figure 6) is that following diol chain-extension, the shape of the first melting peak changes. Comparing the TMP-only formulation to each diol chain-extended formulation, the melting peaks position remains around $200^{\circ} \mathrm{C}$ but changes from a broad to a sharp peak. As the position of the peak is similar in each case, these peaks are believed to originate from the dissociation of domains containing urethane groups of the prepolymer and chain-extender.

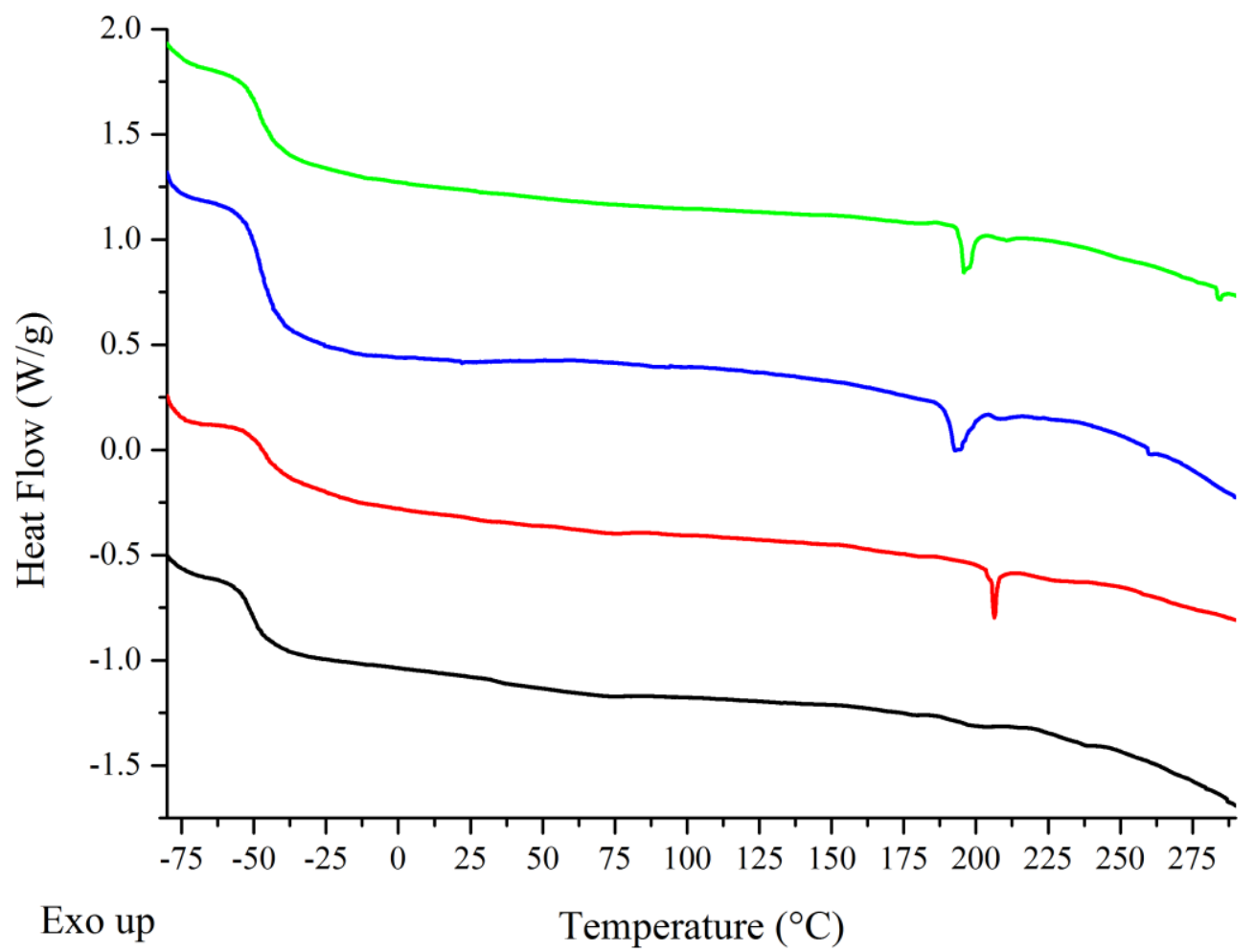

Figure 6: DSC thermograms of the second heating cycle of each IPDI-based MCPU-U. [IPDI-TMP-PCD in black, IPDI-TMP-PCD-DEPD in red, IPDI-TMP-PCD-BD in blue and IPDI-TMP-PCD-PD in grey].

A second weak melting endotherm is observed in all formulations at an elevated temperature. This peak is believed to result from the dissociation of urea-based hard blocks. Small melting enthalpies in each case may result from the concentration of TMP being greater within the 
urea phase. ${ }^{13}$ Mass spectrometry data of the reactive prepolymer formulations shows that, as TMP is present from the start of synthesis, isocyanate-terminated molecules of TMP are present within the formulation (see supplementary data). These reactive moieties will therefore become part of the urea phase following moisture cure. It has been shown by Petrovic that TMP influences the hard-phase architecture through disruption of the packing arrangement, this will broaden and weaken the melting endotherm observed. ${ }^{13}$

Table 4: DSC data for the second heating cycle of each IPDI-based MCPU-U.

\begin{tabular}{ccccccc}
\hline Formulation & $\begin{array}{c}\mathbf{T}_{\mathbf{g}} \mathbf{s p} \\
/{ }^{\circ} \mathbf{C}\end{array}$ & $\begin{array}{c}\mathbf{T}_{\mathrm{g}} \mathbf{s p} \\
\text { Range } \\
/{ }^{\circ} \mathbf{C}\end{array}$ & $\begin{array}{c}\mathbf{T}_{\mathbf{m}} \mathbf{h p 1} \\
/{ }^{\circ} \mathbf{C}\end{array}$ & $\begin{array}{c}\mathbf{T}_{\mathbf{m}} \mathbf{h p 1} \\
\text { Enthalpy } \\
/ \mathbf{J ~ g}^{-1}\end{array}$ & $\begin{array}{c}\mathbf{T}_{\mathbf{m}} \mathbf{h p 2} \\
/{ }^{\circ} \mathbf{C}\end{array}$ & $\begin{array}{c}\mathbf{T}_{\mathbf{m}} \mathbf{h p 2} \\
\text { Enthalpy } \\
/ \mathbf{J ~}^{-1}\end{array}$ \\
\hline $\begin{array}{c}\text { IPDI-TMP-PCD } \\
\text { IPDI-TMP-PCD- } \\
\quad\end{array}$ & -52 & -55 to -45 & 197 & 0.4 & 238 & 0.2 \\
$\begin{array}{c}\text { DEPD } \\
\begin{array}{c}\text { IPDI-TMP-PCD- } \\
\text { BD }\end{array}\end{array}$ & -47 & -51 to -38 & 206 & 0.7 & 227 & 0.2 \\
$\begin{array}{c}\text { IPDI-TMP-PCD- } \\
\text { PD }\end{array}$ & -48 & -52 to -40 & 193 & 1.0 & 208 & 0.1 \\
\hline
\end{tabular}

$T_{g s p}=$ soft-phase glass transition temperature, $T_{m} h p=$ hard-phase peak melt temperature.

The DSC analysis on the MDI based MCPU-U adhesives shows that when TMP is the only chain-extender used, a shift to the soft-phase glass transition temperature ( $\left.\mathrm{T}_{\mathrm{g}} \mathrm{sp}\right)$ of around $+25^{\circ} \mathrm{C}$ is observed. This material is semi-crystalline as both a glass transition and melting of the soft-phase are observed. However, changing the hard-phase architecture using slightly branched diol chain-extenders has resulted in a more phase mixed morphology. This was evident in the additional $+5^{\circ} \mathrm{C}$ to $+10^{\circ} \mathrm{C}$ shift in the $\mathrm{T}_{\mathrm{gsp}}$ and the removal of soft-phase crystallinity. In contrast, diol chain-extension of the IPDI based hard-phase does not result in an amorphous MCPU-U, with each material analysed in the present work being semicrystalline in nature. Therefore, aliphatic IPDI hard blocks are less miscible with PCD than aromatic hard blocks of MDI. The influence that this final semi-crystalline morphology has on the adhesion and clarity will be discussed within section 3.3. 


\subsection{ATR analysis}

\subsubsection{MDI-based formulations}

The main characteristic bands from polymerisation and cure will now be discussed (for spectra see supplementary data). N-H stretching vibrations are positioned between $3150 \mathrm{~cm}^{-1}$ and $3600 \mathrm{~cm}^{-1}$ with hydrogen-bonded and free groups both present. ${ }^{23}$ As there is no clear peak between $2260 \mathrm{~cm}^{-1}$ and $2280 \mathrm{~cm}^{-1}$, the isocyanate signal has fallen below a detectable limit and it can be assumed that the adhesive is fully cured. For each adhesive a large signal from the $\mathbf{C}=\mathbf{O}$ stretching vibration is present between $1630 \mathrm{~cm}^{-1}$ and $1800 \mathrm{~cm}^{-1}$ and contains ester, urethane plus urea functionalities. Full assignments of all characteristic bands are presented within table 5.
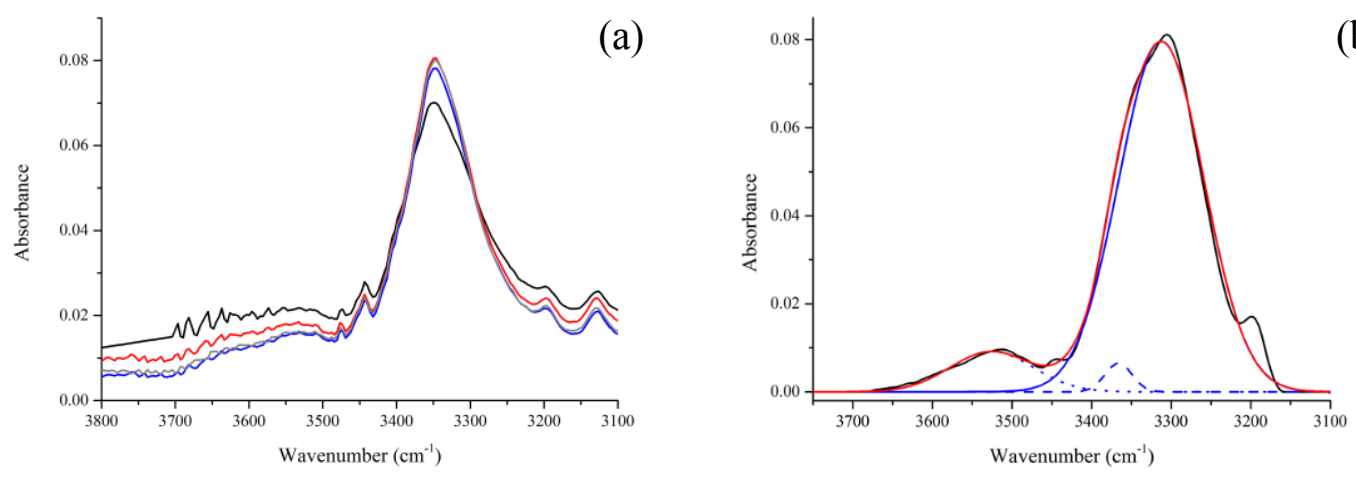

(b)
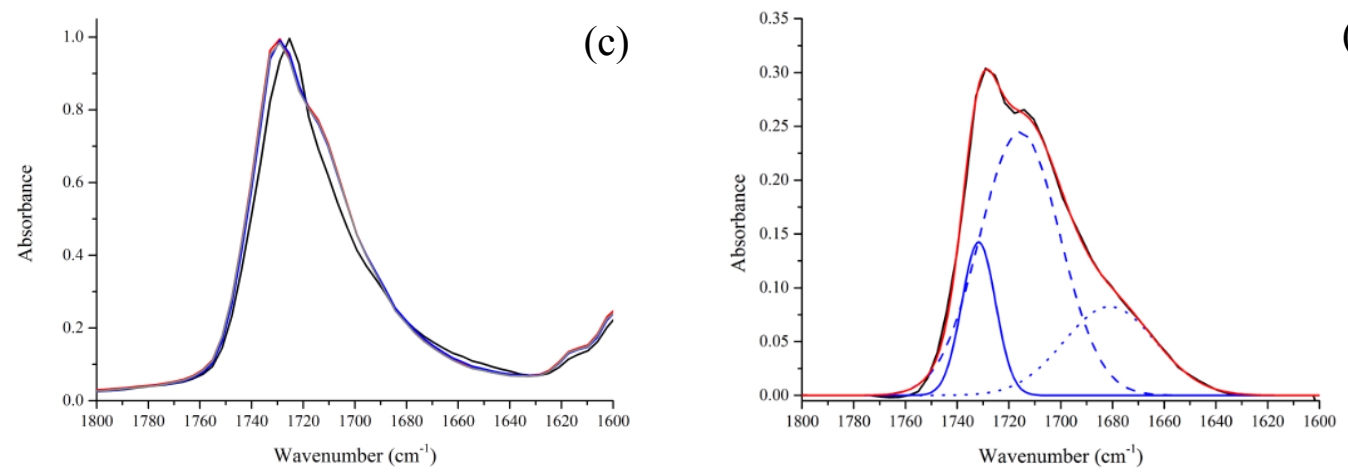

(d)

Figure 7: ATR data collected from each MDI-based MCPU-U adhesive sample. (a) Stacked N-H region, (b) deconvolution example of N-H region for MDI-TMP-PCD, (c) stacked $\mathrm{C}=\mathrm{O}$ region and (d) deconvolution example of $\mathrm{C}=\mathrm{O}$ region for MDI-TMP-PCD. [MDI-TMP-PCD in black, MDI-TMP-PCD-DEPD in red, MDI-TMP-PCD-BD in blue and MDI-TMP-PCD-PD in grey]. 
Greater morphological information can be obtained from closer inspection of both the $\mathbf{N}-\mathbf{H}$ and $\mathbf{C}=\mathbf{O}$ spectral regions (see figure 7). ${ }^{24}$ It is possible by using deconvolution, to obtain information on the order or disorder within these spectral regions. ${ }^{25.26}$ Considering the $\mathbf{N}-\mathbf{H}$ region first, it can be observed that there has been a change in peak shape following diol chain-extension. To understand this change to the $\mathbf{N}-\mathbf{H}$ peak following diol chain-extension, three peaks were fitted. The first of these peaks was fitted between $3400 \mathrm{~cm}^{-1}-3650 \mathrm{~cm}^{-1}$ to determine the free $\mathbf{N}-\mathbf{H}$ groups, a second peak is fitted between $3340 \mathrm{~cm}^{-1}-3400 \mathrm{~cm}^{-1}$ to account for the carbonyl overtone and a final peak is fitted between $3250 \mathrm{~cm}^{-1}-3340 \mathrm{~cm}^{-1}$ to determine the contribution from hydrogen bonded $\mathbf{N}-\mathbf{H}$ groups. ${ }^{26}$

Once analysis was complete, the ratio of hydrogen bonded $\mathbf{N}-\mathbf{H}$ groups to free $\mathbf{N}-\mathbf{H}$ groups can be obtained. Following chain-extension, the ratio decreased from 7:1 for TMP-only to 5.9:1 for DEPD, 5.4:1 for BD and 5.4:1 for PD. In the calculation of hydrogen bonded $\mathbf{N}-\mathbf{H}$ groups no attempt was made to differentiate between hard-to-hard and hard-to-soft interactions. Based on this ratio and the position of the hydrogen bonded N-H peak obtained (see table 6), the quantity of hard-to-hard interactions is reduced following diol chainextension. This reduction in hydrogen bonded $\mathbf{N}-\mathbf{H}$ groups is a consequence of the increased degree of heterogeneity now present within the hard-phase due to the chain-extenders selected. This is consistent with the observation made during DSC analysis where phase mixing increased following diol chain-extension and hard-phase melting enthalpies reduced. What influence greater phase mixing has on the adhesion and clarity will be discussed within section 3.3. 
Table 5: Characteristic ATR bands obtained for each MDI-based MCPU-U synthesised with a different combination of chain-extenders.

\begin{tabular}{|c|c|c|c|c|}
\hline & $\begin{array}{l}\text { MDI-TMP- } \\
\text { PCD }\end{array}$ & $\begin{array}{l}\text { MDI-TMP- } \\
\text { PCD-DEPD }\end{array}$ & $\begin{array}{l}\text { MDI-TMP- } \\
\text { PCD-BD }\end{array}$ & $\begin{array}{l}\text { MDI-TMP- } \\
\text { PCD-PD }\end{array}$ \\
\hline Vibration & $\begin{array}{c}\text { Wavenumber } \\
\qquad\left(\mathrm{cm}^{-1}\right)\end{array}$ & $\begin{array}{c}\text { Wavenumber } \\
\left(\mathrm{cm}^{-1}\right)\end{array}$ & $\begin{array}{c}\text { Wavenumber } \\
\qquad\left(\mathrm{cm}^{-1}\right)\end{array}$ & $\begin{array}{c}\text { Wavenumber } \\
\left(\mathrm{cm}^{-1}\right)\end{array}$ \\
\hline N-H stretching & 3551 & 3346 & 3345 & 3350 \\
\hline $\begin{array}{c}\text { C-H asymmetric } \\
\text { stretch }\end{array}$ & 2943 & 2940 & 2942 & 2944 \\
\hline $\begin{array}{c}\text { C-H symmetric } \\
\text { stretch }\end{array}$ & 2867 & 2864 & 2871 & 2868 \\
\hline $\begin{array}{c}\mathrm{C}=\mathbf{O} \text { stretching } \\
\text { ester }\end{array}$ & 1724 & 1727 & 1726 & 1727 \\
\hline $\begin{array}{c}\text { N-H bending } \\
\text { urethane }\end{array}$ & 1601 & 1597 & 1595 & 1602 \\
\hline $\begin{array}{c}\mathrm{C}-\mathrm{N} \text { stretch, } \mathrm{N}-\mathrm{H} \\
\text { bending, }\end{array}$ & 1534 & 1535 & 1535 & 1526 \\
\hline N-H bending urea & 1515 & 1508 & 1513 & 1512 \\
\hline $\mathrm{C}-\mathrm{H}$ bend aliphatic & 1463 & 1459 & 1470 & 1463 \\
\hline $\begin{array}{c}\text { C-C stretching } \\
\text { aromatic }\end{array}$ & 1411 & 1410 & 1416 & 1419 \\
\hline C-N urea & 1373 & 1365 & 1355 & 1361 \\
\hline C-N urethane & 1307 & 1312 & 1306 & 1312 \\
\hline $\begin{array}{c}\text { C-H aliphatic } \\
\text { skeleton }\end{array}$ & 1221 & 1218 & 1214 & 1223 \\
\hline C-C stretching & 1164 & 1163 & 1154 & 1156 \\
\hline $\begin{array}{c}\text { C-O-C aliphatic } \\
\text { ether }\end{array}$ & 1098 & 1102 & 1094 & 1102 \\
\hline $\mathrm{C}-\mathrm{H}$ aromatic ring & 1060 & 1063 & 1061 & 1067 \\
\hline $\mathrm{C}-\mathrm{H}$ aromatic ring & 965 & 964 & 969 & 964 \\
\hline $\mathrm{C}-\mathrm{H}$ aromatic ring & 871 & 852 & 860 & 853 \\
\hline $\mathrm{C}-\mathrm{H}$ aromatic ring & 808 & 822 & 821 & 812 \\
\hline $\begin{array}{c}\text { C-C aliphatic } \\
\text { skeleton }\end{array}$ & 771 & 772 & 777 & 777 \\
\hline
\end{tabular}


Table 6: Data obtained from deconvolution of $\mathrm{N}-\mathrm{H}$ and $\mathrm{C}=\mathrm{O}$ peaks for each MCPU-U adhesive based on MDI and PCD using Gaussian fitting function.

\begin{tabular}{|c|c|c|c|c|c|c|c|c|c|c|c|c|}
\hline \multirow{3}{*}{ Formulation } & \multicolumn{6}{|c|}{ N-H } & \multicolumn{6}{|c|}{$\mathrm{C}=\mathrm{O}$} \\
\hline & \multicolumn{2}{|c|}{ Free } & \multicolumn{2}{|c|}{$\begin{array}{c}\mathrm{C}=\mathrm{O} \\
\text { Overtone }\end{array}$} & \multicolumn{2}{|c|}{ H-Bonded } & \multicolumn{2}{|c|}{$\begin{array}{l}\text { Free Ester } \\
+ \text { free Ur }\end{array}$} & \multicolumn{2}{|c|}{$\begin{array}{c}\text { H-bonded } \\
\text { Ur }\end{array}$} & \multicolumn{2}{|c|}{$\begin{array}{c}\text { Free } \mathrm{U}+ \\
\text { monodentate }\end{array}$} \\
\hline & $\mathrm{cm}^{-1}$ & $\%$ & $\mathrm{~cm}^{-1}$ & $\%$ & $\mathrm{~cm}^{-1}$ & $\%$ & $\mathrm{~cm}^{-1}$ & $\%$ & $\mathrm{~cm}^{-1}$ & $\%$ & $\mathrm{~cm}^{-1}$ & $\%$ \\
\hline $\begin{array}{l}\text { MDI-TMP- } \\
\text { PCD }\end{array}$ & 3540 & 7.9 & 3351 & 36.1 & 3324 & 56.0 & 1728 & 36.8 & 1712 & 56.7 & 1669 & 6.4 \\
\hline $\begin{array}{l}\text { MDI-TMP- } \\
\text { PCD-DEPD }\end{array}$ & 3544 & 8.9 & 3346 & 38.7 & 3331 & 52.4 & 1733 & 15.2 & 1721 & 65.3 & 1692 & 19.5 \\
\hline $\begin{array}{c}\text { MDI-TMP- } \\
\text { PCD-BD }\end{array}$ & 3546 & 10.5 & 3346 & 33.0 & 3333 & 56.5 & 1732 & 16.2 & 1721 & 60.2 & 1695 & 23.6 \\
\hline $\begin{array}{l}\text { MDI-TMP- } \\
\text { PCD-PD }\end{array}$ & 3547 & 10.0 & 3345 & 36.3 & 3336 & 53.7 & 1733 & 15.2 & 1721 & 66.5 & 1692 & 18.3 \\
\hline
\end{tabular}

$U r=$ urethane, $U=$ urea

Further information on the microphase morphology is obtainable from deconvolution of the carbonyl region. ${ }^{25,26}$ The position of the peak labelled ester within table $\mathbf{6}$, will contain bands from both free urethane and free PCD ester groups which occupy the range $1740 \mathrm{~cm}^{-1}-1730$ $\mathrm{cm}^{-1}$. Of these functionalities, the ester will be dominant and any changes to the environment of these groups will lead to a noticeable change to the peak shape. Following diol chainextension there is a clear change to the peak shape of the carbonyl. When TMP is the only chain-extender, the calculated position of the ester peak is $1728 \mathrm{~cm}^{-1}$ and this confirms that these ester carbonyls are part of the hydrogen bonded network. The previous statement is supported by the observed soft-phase crystalline melting during DSC analysis of MDI-TMPPCD.

A shift of around $5 \mathrm{~cm}^{-1}$ to $1732-1733 \mathrm{~cm}^{-1}$ is observed following diol chain-extension and is accompanied by a change to the peak shape. This shift to higher wavenumbers occurs following a reduction to the order of the hydrogen bond network within the soft-phase between neighbouring PCD chains. ${ }^{27}$ When phase mixing occurs parts of the hard-phase migrate into the soft-phase and introduces heterogeneities to the hydrogen bonding network. Chain mobility will be reduced with the introduction of hard-to-soft interactions during 
mixing. Introducing these interactions into the network has reduced the ability of neighbouring PCD chains to aggregate and crystallise. Urethane carbonyls involved in hardto-soft-phase mixing interactions occurs between $1725 \mathrm{~cm}^{-1}$ and $1730 \mathrm{~cm}^{-1}$ and they will contribute towards the observed shift. The increased number of urethane bonds formed during the chain-extension step will also contribute towards the change in peak shape compared to the TMP-only formulation which has a higher free NCO content prior to cure.

Inspection of the lower wavenumber end of the carbonyl region reveals that there are fewer urea-based carbonyl groups in the diol chain-extended formulations. This reduction in ureabased groups is a consequence of a reduction in the free NCO content as previously mentioned. As crystallisation still occurs in the TMP-only formulation but is absent in the diol chain-extended formulations, it indicates that urea groups have a lower compatibility with the soft-phase compared to urethane groups. This is shown by the larger tail at the lower wavenumber region of the carbonyl peak for the TMP-only spectrum. Urea groups with monodentate $\left(1690\right.$ to $\left.1650 \mathrm{~cm}^{-1}\right)$ and bidentate $\left(1650-1630 \mathrm{~cm}^{-1}\right)$ hydrogen bonds will be present along with non-hydrogen bonded urea $\left(1700-1690 \mathrm{~cm}^{-1}\right){ }^{28}$

\subsubsection{IPDI-based formulations}

For full assignment of each IPDI-based adhesive see table 7 (for spectra see supplementary data). N-H stretching vibrations are positioned between $3150 \mathrm{~cm}^{-1}$ and $3600 \mathrm{~cm}^{-1}$ with hydrogen bonded and free groups both present. ${ }^{23}$ As there is no clear peak between $2260 \mathrm{~cm}^{-}$ ${ }^{1}$ and $2280 \mathrm{~cm}^{-1}$, the isocyanate signal has fallen below a detectable limit and it is assumed that each adhesive is fully cured. For each IPDI-based adhesive a large signal from the $\mathbf{C}=\mathbf{O}$ stretching vibration is present between $1630 \mathrm{~cm}^{-1}$ and $1800 \mathrm{~cm}^{-1}$ and contains ester, urethane plus urea functionalities.

Morphological information is accessible following closer inspection of both the $\mathbf{N}-\mathbf{H}$ and $\mathbf{C}=\mathbf{O}$ spectral regions (see figure 8). ${ }^{27}$ Considering the $\mathbf{N}-\mathbf{H}$ region first, it can be observed that the peak shape is similar for all the IPDI-based adhesives. This contrasts markedly with the behaviour seen in the MDI-based MCPU-U systems. To investigate the ratio of hydrogen bonded to non-hydrogen bonded $\mathbf{N}-\mathbf{H}$ groups, four peaks were fitted to the spectral data. Two peaks are fitted between $3400 \mathrm{~cm}^{-1}-3650 \mathrm{~cm}^{-1}$ to determine the free $\mathbf{N}-\mathbf{H}$ groups, a third peak is fitted between $3340 \mathrm{~cm}^{-1}-3400 \mathrm{~cm}^{-1}$ to account for the carbonyl overtone and a final peak is fitted between $3250 \mathrm{~cm}^{-1}-3340 \mathrm{~cm}^{-1}$ to determine the contribution from hydrogen bonded $\mathbf{N}-\mathbf{H}$ groups. ${ }^{23-25}$ It must be noted that the area calculated for hydrogen 
bonded N-H groups will be the summation of both hard-to-hard and hard-to-soft-phase interactions. For peak positions and calculated areas of each sample see table 8 .
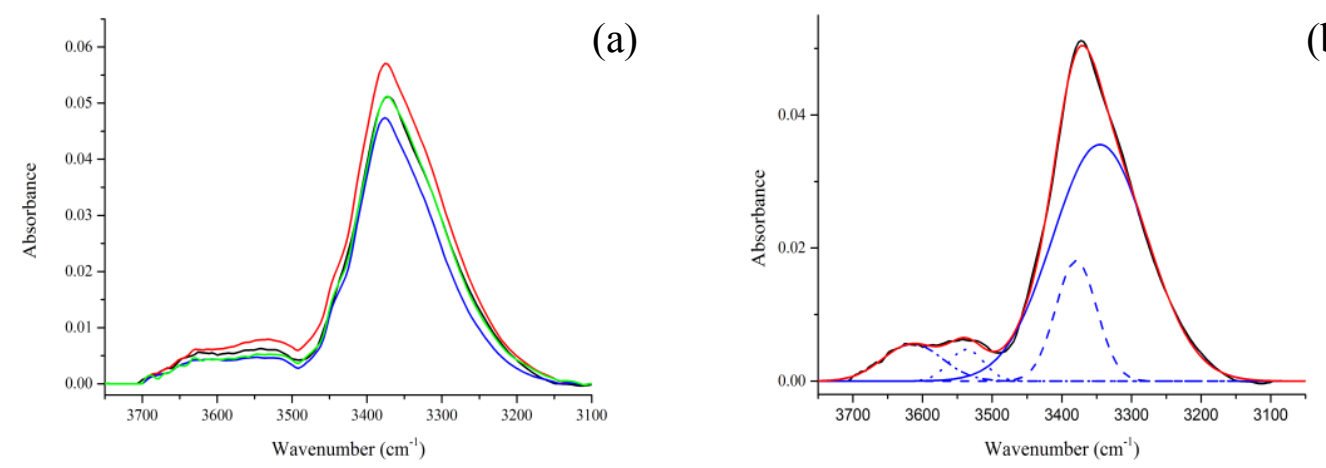

(b)
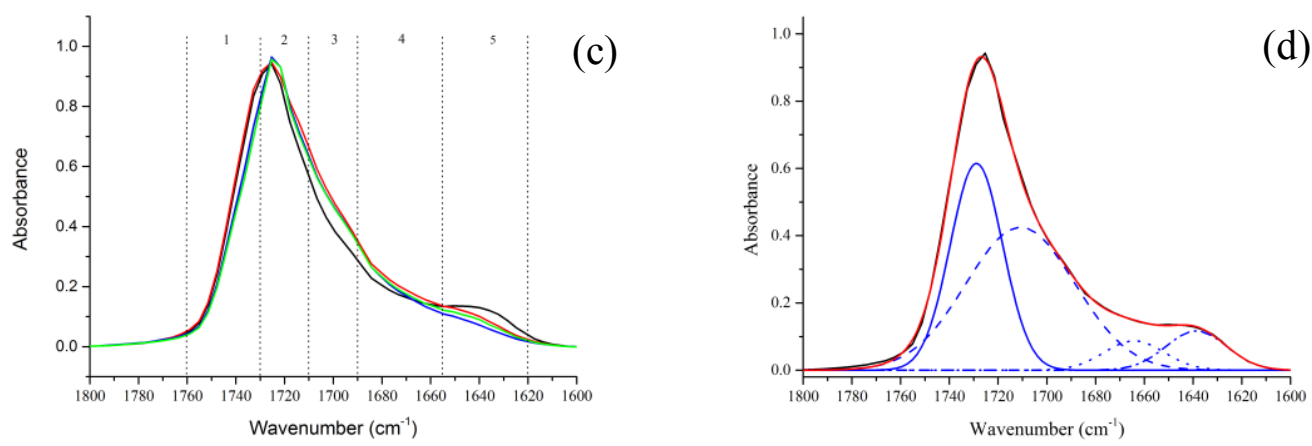

Figure 8: ATR data collected from each IPDI-based MCPU-U adhesive sample. (a) Stacked N-H region, (b) deconvolution example of N-H region for IPDI-TMP-PCD, (c) stacked $\mathrm{C}=\mathrm{O}$ region and $(\mathrm{d})$ deconvolution example of $\mathrm{C}=\mathrm{O}$ region for IPDI-TMP-PCD. [IPDI-TMP-PCD in black, IPDI-TMP-PCD-DEPD in red, IPDI-TMP-PCD-BD in blue and IPDI-TMP-PCD-PD in green]. 
Table 7: Characteristic ATR bands obtained for each IPDI-based MCPU-U synthesised with a different combination of chain-extenders.

\begin{tabular}{|c|c|c|c|c|}
\hline & $\begin{array}{l}\text { IPDI-TMP- } \\
\text { PCD }\end{array}$ & $\begin{array}{l}\text { IPDI-TMP- } \\
\text { PCD-DEPD }\end{array}$ & $\begin{array}{l}\text { IPDI-TMP- } \\
\text { PCD-BD }\end{array}$ & $\begin{array}{l}\text { IPDI-TMP- } \\
\text { PCD-PD }\end{array}$ \\
\hline Vibration & $\begin{array}{l}\text { Wavenumber } \\
\qquad\left(\mathrm{cm}^{-1}\right)\end{array}$ & $\begin{array}{l}\text { Wavenumber } \\
\qquad\left(\mathrm{cm}^{-1}\right)\end{array}$ & $\begin{array}{l}\text { Wavenumber } \\
\qquad\left(\mathrm{cm}^{-1}\right)\end{array}$ & $\begin{array}{c}\text { Wavenumber } \\
\left(\mathrm{cm}^{-1}\right)\end{array}$ \\
\hline $\begin{array}{l}\text { N-H stretching } \mathrm{H}- \\
\text { bonded }\end{array}$ & 3341 & 3336 & 3334 & 3345 \\
\hline C-H stretching & 2981 & 2971 & 2974 & 2980 \\
\hline C-H asymmetric stretch & 2934 & 2928 & 2936 & 2936 \\
\hline C-H symmetric stretch & 2876 & 2871 & 2871 & 2877 \\
\hline $\begin{array}{c}\mathrm{C}=\mathrm{O} \text { stretch Urethane } \\
\text { H-bonded }\end{array}$ & 1715 & 1710 & 1710 & 1715 \\
\hline$C=O$ stretch free Urea & 1699 & 1700 & 1699 & 1700 \\
\hline $\begin{array}{c}\mathrm{C}=\mathrm{O} \text { stretch Urea } \\
\text { Bidentate H-bonded }\end{array}$ & 1648 & 1640 & 1644 & 1644 \\
\hline C-N stretch, N-H bend & 1530 & 1530 & 1535 & 1535 \\
\hline C-H bend aliphatic & 1463 & 1463 & 1453 & 1453 \\
\hline $\begin{array}{l}\text { C-H methyl } \\
\text { deformation }\end{array}$ & 1378 & 1373 & 1372 & 1367 \\
\hline C-N Urea & 1340 & 1340 & 1350 & 1345 \\
\hline C-N Urethane & 1307 & 1307 & 1306 & 1301 \\
\hline $\begin{array}{l}\text { Asymmetric N-CO-O, } \\
\text { C-H aliphatic skeleton }\end{array}$ & 1231 & 1230 & 1246 & 1241 \\
\hline $\begin{array}{c}\text { C-O-C stretch aliphatic } \\
\text { ether }\end{array}$ & 1093 & 1102 & 1094 & 1094 \\
\hline Symmetric N-CO-O & 1016 & 1022 & 1017 & 1012 \\
\hline $\begin{array}{c}\text { C-O-C stretch aliphatic } \\
\text { ether }\end{array}$ & 932 & 922 & 925 & 925 \\
\hline C-C skeleton vibration & 866 & 870 & 870 & 865 \\
\hline C-C skeleton vibration & 833 & 841 & 832 & 832 \\
\hline C-C skeleton rocking & 775 & 775 & 778 & 772 \\
\hline
\end{tabular}


Following deconvolution of the $\mathbf{N}-\mathbf{H}$ region, it is possible to calculate the ratio of hydrogen bonded to non-hydrogen bonded groups. This makes it possible to characterise any changes to the final microphase structure as any difference in the $\mathbf{N}-\mathbf{H}$ configuration will result in a peak shift.

For the TMP-only formulation, the calculated ratio is 7:1. Following chain-extension, the ratio obtained is similar with the exception of IPDI-TMP-PCD-DEPD. The ratios obtained are 4:1 for IPDI-TMP-PCD-DEPD, 7:1 for IPDI-TMP-PCD-BD and 8:1 for IPDI-TMP-PCDPD. This lower ratio obtained would be expected due to DEPD being the bulkiest of the chain-extenders which will introduce the greatest heterogeneity to the hard-phase. Having a poor packing arrangement within the hard-phase will lead to a greater degree of phase mixing, which is consistent with DSC data. This observation is consistent with previous results for MDI.

Table 8: Data obtained from deconvolution of $\mathrm{N}-\mathrm{H}$ and $\mathrm{C}=\mathrm{O}$ peaks for each MCPU-U adhesive based on IPDI and PCD using Gaussian fitting function.

\begin{tabular}{|c|c|c|c|c|c|c|c|c|c|c|c|c|c|c|}
\hline \multirow{3}{*}{ Adhesive } & \multicolumn{6}{|c|}{ N-H } & \multicolumn{8}{|c|}{$\mathbf{C}=\mathbf{O}$} \\
\hline & \multicolumn{2}{|c|}{ Free } & \multicolumn{2}{|c|}{$\begin{array}{c}\mathrm{C}=\mathrm{O} \\
\text { Overtone }\end{array}$} & \multicolumn{2}{|c|}{ H-Bonded } & \multicolumn{2}{|c|}{$\begin{array}{c}\text { Free Ur }+ \\
\text { Ester }\end{array}$} & \multicolumn{2}{|c|}{$\begin{array}{c}\text { H-Bonded } \\
\text { Ur }\end{array}$} & \multicolumn{2}{|c|}{$\begin{array}{l}\text { Monode } \\
\text { ntate U }\end{array}$} & \multicolumn{2}{|c|}{$\begin{array}{c}\text { Bidentate } \\
\text { U }\end{array}$} \\
\hline & $\mathrm{cm}^{-1}$ & $\%$ & $\mathrm{~cm}^{-1}$ & $\%$ & $\mathrm{~cm}^{-1}$ & $\%$ & $\mathrm{~cm}^{-1}$ & $\%$ & $\mathrm{~cm}^{-1}$ & $\%$ & $\mathrm{~cm}^{-1}$ & $\%$ & $\mathrm{~cm}^{-1}$ & $\%$ \\
\hline 1 & $\begin{array}{c}3614 \\
+ \\
3537\end{array}$ & 11 & 3379 & 16 & 3345 & 73 & 1729 & $\begin{array}{l}3 \\
5\end{array}$ & 1711 & 51 & 1664 & 6 & 1639 & 8 \\
\hline 2 & $\begin{array}{c}3613 \\
+ \\
3537\end{array}$ & 18 & 3380 & 16 & 3350 & 66 & 1729 & $\begin{array}{l}2 \\
8\end{array}$ & 1712 & 59 & 1670 & 6 & 1644 & 7 \\
\hline 3 & $\begin{array}{c}3613 \\
+ \\
3537\end{array}$ & 10 & 3381 & 16 & 3351 & 74 & 1727 & $\begin{array}{l}3 \\
0\end{array}$ & 1710 & 62 & 1668 & 1 & 1649 & 7 \\
\hline 4 & $\begin{array}{c}3610 \\
+ \\
3525\end{array}$ & 9 & 3377 & 17 & 3346 & 74 & 1727 & $\begin{array}{l}2 \\
9\end{array}$ & 1710 & 62 & 1668 & 1 & 1647 & 8 \\
\hline
\end{tabular}

$U r=$ urethane, $U=$ urea, $1=$ IPDI-TMP-PCD, $2=$ IPDI-TMP-PCD-DEPD, 3 = IPDI-TMP-

PCD-BD, 4 = IPDI-TMP-PCD-PD. 
The lower miscibility of IPDI based hard blocks with PCD compared to MDI is shown by the position of the calculated hydrogen bonded peak. For IPDI, this hydrogen bonded N-H peak was calculated to occur between $3345 \mathrm{~cm}^{-1}-3351 \mathrm{~cm}^{-1}$. For the MDI-based formulations, this hydrogen bonded N-H peak was calculated to occur between $3324 \mathrm{~cm}^{-1}-3336 \mathrm{~cm}^{-1}$. This $+20 \mathrm{~cm}^{-1}$ shift displays that the contribution from hard-to-soft-phase interactions is much reduced. ${ }^{27}$ A reduced contribution of these interactions supports the argument that hard block of IPDI are less miscible with PCD that those of MDI.

Complementary information on the morphology can be obtained from deconvolution of the carbonyl region. ${ }^{24}$ Again, there is a contrast to the MDI-formulations. With MDI, there was a clear change in the carbonyl peak shape following chain-extension due to the removal of softphase crystallisation - a $5 \mathrm{~cm}^{-1}$ shift was observed from $1728 \mathrm{~cm}^{-1}$ for the TMP-only formulation to $1732-1733 \mathrm{~cm}^{-1}$ for the diol chain-extender formulations. For the IPDI adhesives this change in peaks shape is not observed as all materials retain a semi-crystalline morphology. This is reflected in the calculated position of the peak corresponding to free urethane and ester which is found within the range $1727-1729 \mathrm{~cm}^{-1}$. Each carbonyl peak for these IPDI based formulations is within the characteristic region of a hydrogen bonded ester group which is consistent with DSC analysis. ${ }^{27}$ There will also be free urethane carbonyl groups present within this peak between $1725 \mathrm{~cm}^{-1}$ and $1730 \mathrm{~cm}^{-1}$. It is believed based on the peak shape and DSC analysis that the contribution from these groups will be similar in each case and therefore, the peak position will not be greatly affected.

At the lower wavenumber end of the carbonyl peak there is a visible difference between the TMP-only and diol chain-extended formulations. The greater proportion of urea-based functional groups in the TMP-only spectrum is inherent of this formulation having a greater residual isocyanate content prior to cure. These groups are consumed during prepolymer formulation by the diol chain-extender. Therefore each spectrum containing a diol chainextender has a greater shoulder from hydrogen bonded urethane groups between $1730 \mathrm{~cm}^{-1}$ and $1710 \mathrm{~cm}^{-1}$. Present in both MCPU-U adhesives is mono- and bi-dentate hydrogenbonded urea. These groups will reside within the hard-phase and contribute towards the matrix strength of the adhesive. The contribution from these hydrogen-bonded urea groups is greater in these IPDI based formulations than was observed for MDI previously. This observation further supports the argument that the miscibility of an IPDI based hard-phase with PCD is lower than that of a MDI based hard-phase. 


\subsection{Adhesive strength and clarity}

DSC and ATR data indicate that phase mixing is increased following the introduction of a diol chain-extender, the effect that this change to the morphology has on the adhesive properties and clarity will now be discussed. Within the literature to the best of the authors' knowledge there is no data on the bond strength of PC laminates containing a MCPU-U adhesive. Values for materials such as poly(vinyl chloride) (PVC) and polyimide (PI) have been reported within the literature. ${ }^{5,14,29}$ Sanchez-Adsuar et al. reported peel strengths of $6 \mathrm{~N}$ $\mathrm{mm}^{-1}$ to $8 \mathrm{~N} \mathrm{~mm}^{-1}$ for PVC laminates using linear polyurethanes containing MDI, PCD and 1,4-butane diol. ${ }^{5}$ A relationship was constructed that linked the peel strength obtained to the synthesis time of the prepolymer. Prepolymer reaction times of $\geq 3$ hours and chainextension times of $\geq 8$ hours yielded the greatest peel strengths. ${ }^{5}$ No mention of the adhesive clarity was disclosed within the study but as large melting endotherms were recorded during thermal analysis we expect that the adhesive layer will have been opaque due to crystallites. Leitsch et al. obtained comparable values for PVC using a similar polyurethane based on toluene diisocyanate, poly(propylene glycol) and 1,4-butane diol. They also reported peel strengths of around $5 \mathrm{~N} \mathrm{~mm}^{-1}$ for PI. ${ }^{29} \mathrm{Li}$ and Sun reported data on the T-peel strength of a waterborne aliphatic PU-U system based on a soft-phase of 1,4-butylene adipate. ${ }^{30}$ Within this paper, the peel strength was shown to vary between $5.4 \mathrm{~N} \mathrm{~mm}^{-1}$ to $6.8 \mathrm{~N} \mathrm{~mm}^{-1}$ depending on the stoichiometry, which was varied from 1.3 to 1.9 . The maximum peel strength of $8.1 \mathrm{~N}$ $\mathrm{mm}^{-1}$ was obtained for the PVC joint with a stoichiometry if 1.5 . Within the same paper it was shown that peel strength increased as the soft-phase length is increased. García-Pacios et al. investigated what influence the solid content has on the final properties of waterborne polyurethanes based on the polycarbonate of hexane diol. ${ }^{31}$ Within that study, PVC joints were tested to determine the peel strengths for solid content between $37 \mathrm{wt} \%$ to $44 \mathrm{wt} \%$. The peel value obtained varied between $1.0 \mathrm{~N} \mathrm{~mm}^{-1}$ to $1.2 \mathrm{~N} \mathrm{~mm}^{-1}$, which implies that the solids content has a minimal impact on the strength obtained.

Table 9 displays the data collected during $180^{\circ}$ T-peel testing of each adhesive following 1 week, 1 month and 18 months of room temperature cure. Peel strengths obtained within the current study using PC are comparable to values obtained on PVC but are of greater strength than PI following 1 month of cure. On untreated PC all peel strengths were above bench mark and ranged from $4.8 \mathrm{~N} \mathrm{~mm}^{-1}$ to $8.2 \mathrm{~N} \mathrm{~mm}^{-1}$. This also applies to $\mathrm{PC}(\mathrm{t})$ as all peel strength values recorded were above bench mark and ranged from $4.0 \mathrm{~N} \mathrm{~mm}^{-1}$ to $8.3 \mathrm{~N} \mathrm{~mm}^{-1}$ following 1 month cure. After 18 months of cure, the peel strength for each adhesive was 
lower than the value obtained after 1 month. As all modes of failure were still adhesive at the interface, the adhesive matrix may be relaxing with time resulting in a reduced number of donor - acceptor type interactions with the substrate.

For the MDI-based adhesives, on untreated PC MDI-TMP-PCD yields the highest peel strength of $8.2 \mathrm{~N} \mathrm{~mm}^{-1}$ after curing for 1 month. Following diol chain-extension there is a net reduction in the peel strength obtained at 1 month with a $41 \%$ reduction in MDI-TMP-PCDDEPD, 20\% reduction for MDI-TMP-PCD-BD and a 30\% reduction in MDI-TMP-PCD-PD. The same trend was observed after 18 months with MDI-TMP-PCD yielding the highest peel strength of $6.9 \mathrm{~N} \mathrm{~mm}^{-1}$ with PC. As each formulation has a similar hard-segment content this decrease in peel strength cannot be attribute to this small difference (range $22.3 \%-26.1 \%$ ). The difference in peel strength must therefore be related to the morphology of the fully cured adhesive system. The DSC and ATR-IR data showed that of the MDI-based adhesives, MDITMP-PCD had the highest degree of phase separation and the relationship between morphology and performance is readily apparent. With the addition of the diol chainextenders comes an increase in the degree of phase mixing and a drop in peel strength. The consequence of increasing the degree of phase mixing within the adhesive is a reduced ability to adhere with PC substrate whether pre-treated or not. Beneficial interactions such as hydrogen bonding, van der Waals and $\pi-\pi$ ring stacking interactions will be reduced. These are the predicted modes of adhesion as all MCPU-Us failed adhesively at the interface. Due to the intrinsic low hard-segment content, the potential for the adhesive to form covalent bonds with the interface will be limited as most reactive isocyanate groups will be consumed in network formation. Even with each adhesive operating well above its $\mathrm{T}_{\mathrm{gSs}}$, soft-segment chains in the diol chain-extended formulations will be under a higher degree of conformational constraint compared to MDI-TMP-PCD. This will reduce the ability of the adhesive to come into intimate contact with the substrate and therefor the final peel strength will be reduced. Peel strength values after 18 months are lower than 1 month values. This reduction in strength may result from the relaxation of internal stresses within the network with time. Coupled with the reduction in peel strength as a result of phase mixing is, however, a measurable improvement in clarity. Adhesive MDI-TMP-PCD has the worst clarity at $63.4 \%$ for $\mathrm{PC}$ and $62.6 \%$ for $\mathrm{PC}(\mathrm{t})$. This formulation has the greatest degree of phase separation and will therefore have the lowest amount of heterogeneity within the softphase. From DSC analysis of this formulation, the calculated value of Xc was $4.7 \%$. Thus, even following a greater than 8-fold reduction in the Xc value (PCD is $40.1 \%$ ), an adhesive 
layer of high haze will be obtained. Following diol chain-extension, a significant increase in clarity is obtained with an $>50$-fold increase for DEPD; $>40$-fold increase for BD; and a $>$ 90-fold increase for PD. Rationally altering the hard-phase architecture has resulted in the retardation of soft-phase crystallisation. By controlling the architecture of the hard-phase it is possible to control the final morphology and design high clarity adhesives (see in section 3.4).

Table 9: Peel strength data obtained for each MCPU-U adhesive.

\begin{tabular}{|c|c|c|c|c|c|c|}
\hline $\begin{array}{c}\text { Adhesive } \\
\text { Formulation }\end{array}$ & Laminate & $\begin{array}{l}\text { Peel 1* } \\
\left(\mathrm{N} \mathrm{mm}^{-1}\right)\end{array}$ & $\begin{array}{c}\text { Peel 2x } \\
\left(\mathrm{N} \mathrm{mm}^{-1}\right)\end{array}$ & $\begin{array}{c}\text { Peel 3y } \\
\left(\mathrm{N} \mathrm{mm}^{-1}\right)\end{array}$ & $\begin{array}{c}\text { Failure } \\
\text { mode }\end{array}$ & $\begin{array}{c}\text { Clarity } \\
(\%)\end{array}$ \\
\hline MDI-TMP- & $\mathrm{PC}(\mathrm{t}) / \mathrm{PC}(\mathrm{t})$ & 7.7 & 8.3 & 6.0 & Adhesive & 62.6 \\
\hline PCD & $\mathrm{PC} / \mathrm{PC}$ & 7.6 & 8.2 & 6.9 & Adhesive & 63.4 \\
\hline MDI-TMP- & $\mathrm{PC}(\mathrm{t}) / \mathrm{PC}(\mathrm{t})$ & 3.2 & 4.0 & 3.6 & Adhesive & 1.1 \\
\hline PCD-DEPD & $\mathrm{PC} / \mathrm{PC}$ & 4.6 & 4.8 & 4.5 & Adhesive & 1.2 \\
\hline MDI-TMP- & $\mathrm{PC}(\mathrm{t}) / \mathrm{PC}(\mathrm{t})$ & 5.5 & 4.6 & 4.2 & Adhesive & 1.6 \\
\hline PCD-BD & $\mathrm{PC} / \mathrm{PC}$ & 6.3 & 6.6 & 4.5 & Adhesive & 1.4 \\
\hline MDI-TMP- & $\mathrm{PC}(\mathrm{t}) / \mathrm{PC}(\mathrm{t})$ & 4.4 & 4.6 & 4.7 & Adhesive & 0.4 \\
\hline PCD-PD & $\mathrm{PC} / \mathrm{PC}$ & 5.3 & 5.7 & 5.0 & Adhesive & 0.7 \\
\hline IPDI-TMP- & $\mathrm{PC}(\mathrm{t}) / \mathrm{PC}(\mathrm{t})$ & 5.5 & 5.1 & 3.2 & Adhesive & 82.2 \\
\hline PCD & $\mathrm{PC} / \mathrm{PC}$ & 8.1 & 10.5 & 4.9 & Adhesive & 80.2 \\
\hline IPDI-TMP- & $\mathrm{PC}(\mathrm{t}) / \mathrm{PC}(\mathrm{t})$ & 5.5 & 5.3 & 3.5 & Adhesive & 77.6 \\
\hline PCD-DEPD & $\mathrm{PC} / \mathrm{PC}$ & 2.5 & 2.3 & 1.6 & Adhesive & 68.4 \\
\hline IPDI-TMP- & $\mathrm{PC}(\mathrm{t}) / \mathrm{PC}(\mathrm{t})$ & 0.4 & 4.7 & 2.7 & Adhesive & 81.8 \\
\hline PCD-BD & $\mathrm{PC} / \mathrm{PC}$ & 0.5 & 9.2 & 3.1 & Adhesive & 82.5 \\
\hline IPDI-TMP- & $\mathrm{PC}(\mathrm{t}) / \mathrm{PC}(\mathrm{t})$ & 0.3 & 7.8 & 1.4 & Adhesive & 66.3 \\
\hline PCD-PD & $\mathrm{PC} / \mathrm{PC}$ & 0.4 & 9.9 & 3.2 & Adhesive & 71.7 \\
\hline
\end{tabular}

* Peel 1 collected within 1 week of room temperature cure, ${ }^{x}$ peel 2 collected after 1 month of room temperature cure and ${ }^{y}$ Peel 3 collected after 18 months of room temperature cure. 
For the IPDI-based formulations, the maximum strength in PC/PC samples was obtained following 1 month of cure with values ranging from $5.3 \mathrm{~N} \mathrm{~mm}^{-1}$ to $10.5 \mathrm{~N} \mathrm{~mm}^{-1}$. From these values, it would appear that only chain-extender DEPD has affected the peel strength. Also evident in the current set of data is a net reduction in peel strength when measured after 18 months. The measured reduction to the peel strength value is $53 \%$ for IPDI-TMP-PCD, 30\% for IPDI-TMP-PCD-DEPD, 66\% for IPDI-TMP-PCD-BD and 68\% for IPDI-TMP-PCD-PD. This results in adhesive IPDI-TMP-PCD-DEPD falling out with the accepted minimum peel strength value of $3 \mathrm{~N} \mathrm{~mm}^{-1}$. The mode of failure for each 1 month and 18 month test is adhesive at the PC interface. Therefore, the observed reduction in peel strength must result following a reorganisation of the adhesive morphology at the adhesive - PC interface. It is believed that this reorganisation within the adhesive reduces the number of hydrogen bonds with the PC interface resulting in a lower peel strength, This, however, this would require further analysis to confirm.

For both MDI and IPDI systems, the results obtained show that it is clear that surface treatment with ethanolamine has no beneficial effect and in most instances the peel strength was reduced. For example, for the IPDI systems, data collected from each of the ethanolamine surface treated samples display lower peel strengths compared to PC with IPDI-TMP-PCD-DEPD being the only exception. This reduced peel strength following surface treatment shows that changing the substrate interface via chemical treatment has affected the adsorption chemistry. At 1 month all peel values obtained are $>3 \mathrm{~N} \mathrm{~mm}^{-1}$ with IPDI-TMP-PCD-BD recording the highest strength of $7.8 \mathrm{~N} \mathrm{~mm}^{-1}$. Unlike was observed with samples of PC, the chain-extender combination appears to have no influence on the strength. After 18 months, lower peel values are obtained for each adhesive which is consistent with what was observed with PC. The measured reduction in peel strength is $37 \%$ for IPDI-TMPPCD, 34\% for IPDI-TMP-PCD-DEPD, $42 \%$ for IPDI-TMP-PCD-BD and $82 \%$ for IPDITMP-PCD-PD. After 18 months, adhesives of formulation IPDI-TMP-PCD-BD and IPDITMP-PCD-PD have fallen below the minimum accepted strength value of $3 \mathrm{~N} \mathrm{~mm}^{-1}$. As each sample fails adhesively at the PC(t) interface it displays that the interactions between the MCPU-U adhesive and PC(t) are no longer the same. As with PC, it is believed that this net reduction is due to a morphological reorganisation. As the soft-phase is well above it glass transition, reorganisation may occur within this phase between PCD chains. Consequently soft-phase crystallinity will increase and reduce the number of hydrogen bonding interactions 
with the interface. To correctly identify the specific mode of reorganisation within the MCPU-U adhesive further analysis will be required.

There are two possible reasons why the treatment is non-beneficial: firstly as each adhesive has a high viscosity at room temperature the mobility of the low number of free isocyanate groups will be limited making the probability of finding either a hydroxyl or phenol group at the interface unlikely; secondly the treatment may roughen the interface on a molecular level and therefore disrupt the adsorption chemistry occurring.

\subsection{Morphology models}

Following the above analysis it is possible to construct morphological models of the microphase structure. By constructing such morphological models, the difference in the microphase structure pre and post diol chain-extension can be represented. The same models can then be used to explain what microphase structure is beneficial for peel strength and which is beneficial for adhesive clarity.

Using DSC and ATR it was identified that the microphase morphology in the TMP-only MDI-based formulation was different versus the formulations which contain a diol chainextender. Two differences were observed: firstly in the TMP-only formulation crystallisation of the soft-segment occurs which was absent in each diol chain-extended formulation, secondly the $\mathrm{T}_{\mathrm{gSS}}$ of each diol chain-extended formulation shifts to a higher temperature and becomes broader. As the TMP-only formulation has crystalline regions within the soft-phase it indicates that following diol chain-extension the morphology becomes more mixed. This is supported by ATR analysis where the ester carbonyl peak moved to a higher wavenumber due to a reduction in ester hydrogen bonding order. Greater phase mixing is further supported by the broadening and elevation of the $T_{g}$ ss following diol chain-extension. ATR data supports this observation as soft-to-hard carbonyl interactions will influence the shift to higher wavenumbers $\left(1725 \mathrm{~cm}^{-1}-1730 \mathrm{~cm}^{-1}\right)$. Data collected from the N-H peak also supports greater phase mixing, as the ratio of order to disorder is reduced and confirms a less ordered hard-phase.

Migration of the hard-phase into the soft-phase of the MDI-based formulations was apparent by the reduction in the melting enthalpy for the hard-phase. In each case where a diol chainextender is used, the total hard-phase melting enthalpy is reduced. This suggests that the 
hard-phase is either more dispersed or less organised. The proposed model structures are presented within figure 9 with (a) showing the microphase morphology when TMP is the lone chain-extender and (b) showing the microphase structure when a combination of chainextenders is used. It is believed that in going from (a) to (b) parts of the hard-phase penetrate the soft-phase and in doing so stop soft-phase crystallisation. Based on DSC analysis crystallisation is removed as no melting endotherm is observed. This takes the soft-phase morphology from semi-crystalline in (a) to amorphous in (b). Phase mixing can be identified as the contributing factor to improving the haze from $63.4 \%$ to $1.6 \%$ or lower. Phase mixing of this type is encouraged by the structure of the diol chain-extenders which clearly influences the hard-phase's organisation.

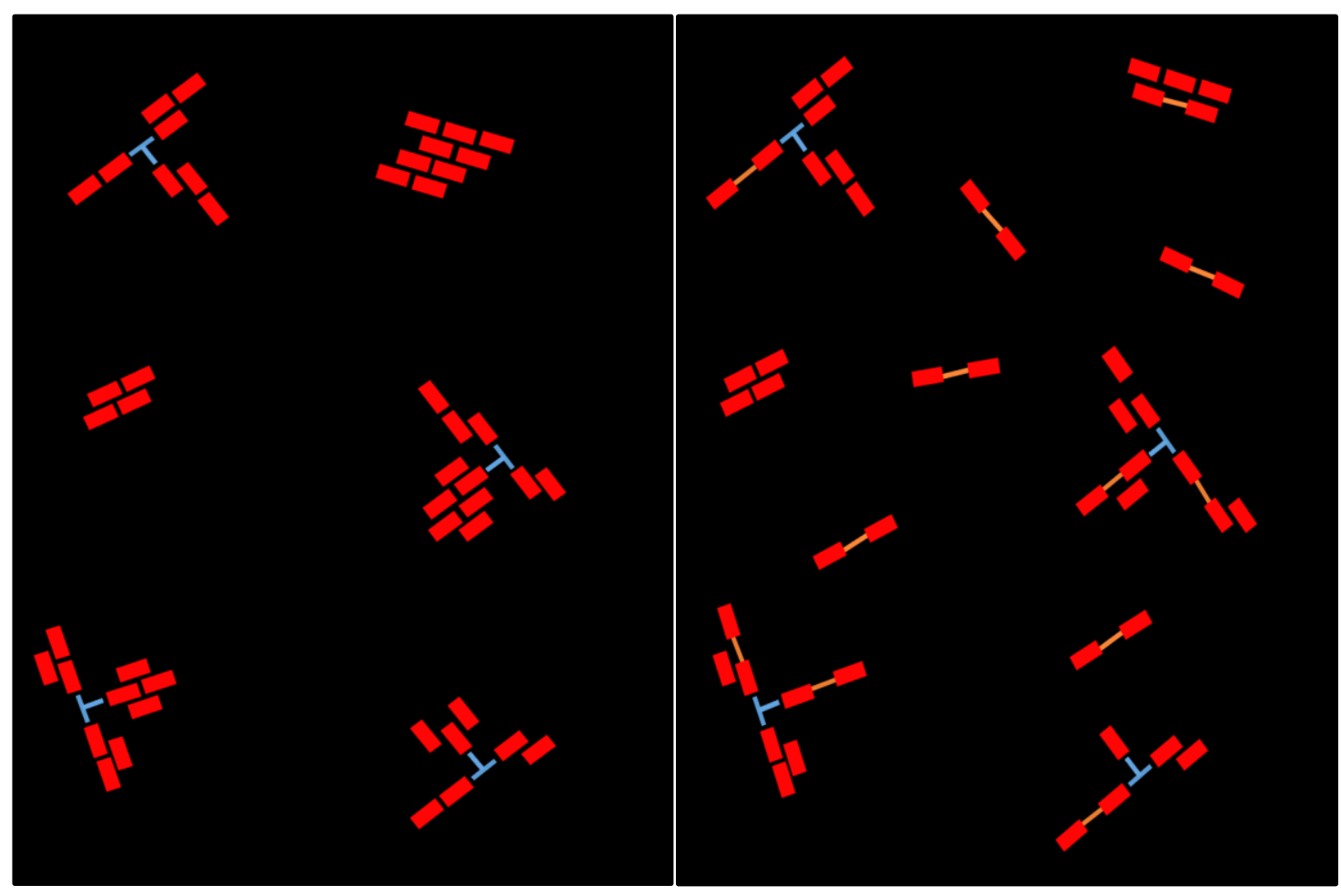

Figure 9: Morphological models of the MDI-based MCPU-U adhesives. (a) Morphology in TMP-only formulation and (b) morphology in diol chain-extended formulations. [Thin black line $=$ amorphous soft-phase, thick black line $=$ ordered soft-phase, red rectangle $=$ MDI hard-phase, blue $\mathrm{T}$-shape $=$ TMP chain-extender and orange line $=$ diol chain-extender].

The model helps to display that phase mixing has an overall reducing effect on the peel strength recorded. From the data collected it is shown that a phase-separated morphology is 
more beneficial for adhesive bonding. Supporting this observation is the TMP-only formulation having the highest peel strength during every peel test on both $\mathrm{PC}$ and $\mathrm{PC}(\mathrm{t})$. During phase mixing potential donor - acceptor groups will be consumed by hard-to-soft interactions. This leaves the number of donors - acceptor groups available to the substrate reduced. Therefore the net result is a reduced peel strength in each case. From the above models it can therefore be drawn that phase separation leads to greater peel strengths while phase mixing leads to improved clarity. Construction of the model has shown that it is possible by understanding the microphase structure to design optically clear adhesives of high peel strength.

For the IPDI-based formulations, IPDI-TMP-PCD has the greatest degree of phase separation as $\mathrm{TgSp}_{\mathrm{g} p}$ has the narrowest range and it occurs at the lowest temperature. This is consistent with the observation for the MDI-based formulations that the diol chain-extenders of the type promote phase mixing. Further evidence that IPDI-TMP-PCD has a slightly different morphology to each of the diol chain-extended formulations is shown in the soft-phase melting enthalpy. Within this formulation, the depression of the melting peak is negligible compared to $\mathrm{PCD}$ and remains at $50^{\circ} \mathrm{C}$. This suggests that the crystalline domains within the soft-phase are well ordered. ${ }^{10,21}$ Initial heat DSC scans show that IPDI-TMP-PCD has the highest enthalpy of melting of all the analysed MCPU-Us. Therefore, the soft-phase within this formulation will have the lowest hard-phase mixing compared to the other formulations.

From these observations it is possible to construct morphological models for the two different morphologies as shown in figure 10. Model (a) represents the structure observed within formulation IPDI-TMP-PCD and displays greater phase separation whereas model (b) displays the more phase mixed morphology of the diol chain-extended formulations. Apparent from the strength data is that this slight change to the morphology has a limited impact on the peel strength obtained (see section 3.3). Significant within both models are large areas of soft-phase order. These regions in models (a) and (b) represent the large crystalline moieties that interact with visible light and correspond to the high haze values obtained (compare with the morphologies in figure 9). The scattering of light by these crystallite domains results in each final adhesive being of low clarity. 

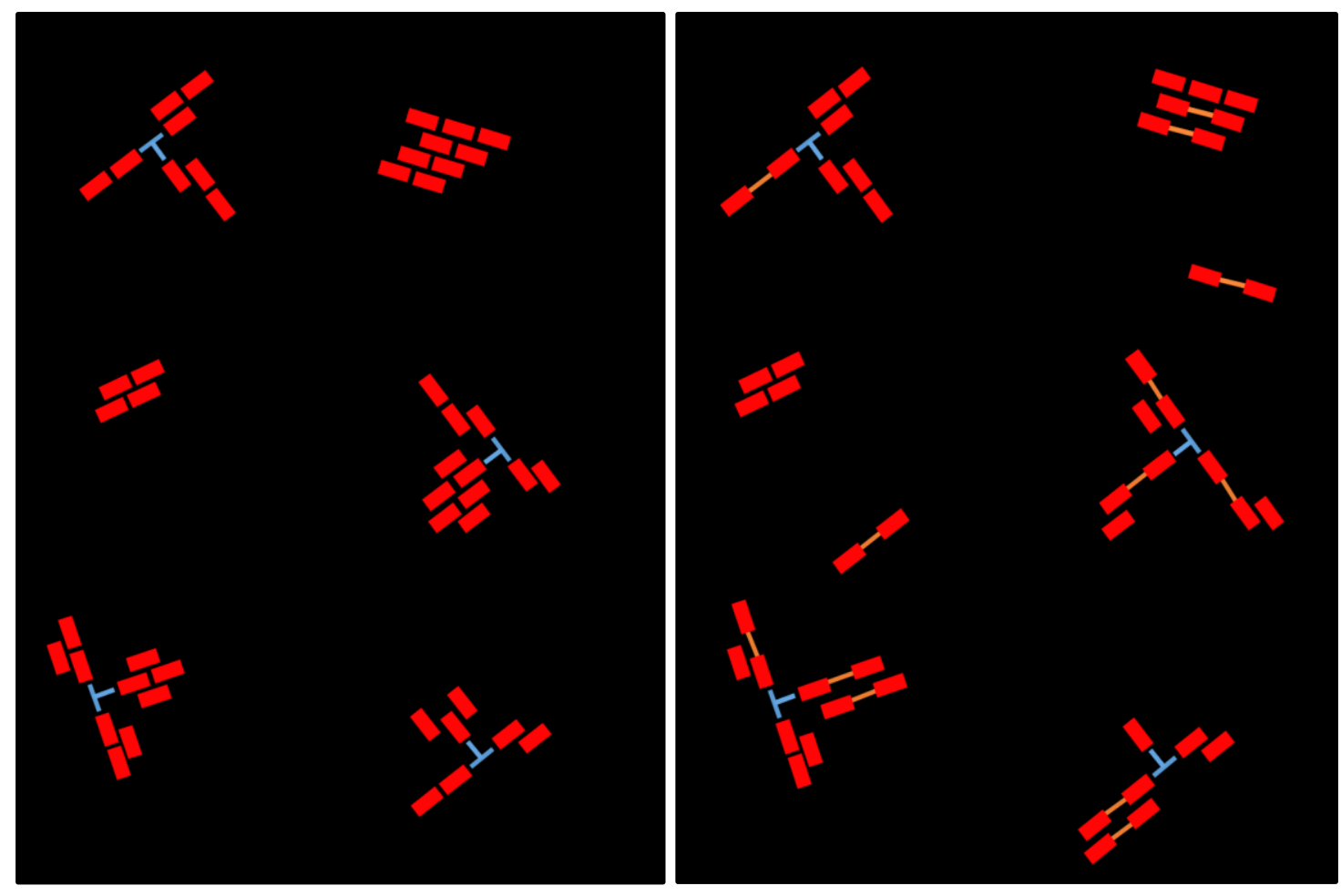

Figure 10: Morphological models of the IPDI-based MCPU-U adhesives. (a) Morphology in TMP-only formulation and (b) morphology in diol chain-extended formulations. [Thin black line $=$ amorphous soft-phase, thick black line $=$ ordered softphase, red rectangle $=$ IPDI hard-phase, blue $\mathrm{T}$-shape $=$ TMP chain-extender and orange line $=$ diol chain-extender].

\section{Conclusions}

It has been demonstrated that MCPU-Us based on MDI or IPDI and PCD are suitable adhesives for bonding flexible PC substrates, although only chain-extended MDIformulations offer optical clarity. Generally, MDI-based formulations showed higher peel strengths and of the eight formulations synthesised, MDI-TMP-PCD resulted in the highest 18-month peel strength of $6.9 \mathrm{~N} \mathrm{~mm}^{-1}$ but at the cost of high haze. High peel strength values are obtained regardless of which substrate interface was used. It can be concluded that using diol chain-extenders which contain side groups affect the microphase structure of the final MCPU-U. Due to the disruptive nature of each chain-extender, association of the hardsegments was reduced and this results in greater phase mixing. By increasing the degree of phase mixing it is possible to remove crystallisation of the soft-phase which leads to much improved clarity. Therefore, from this data another conclusion is observed, that even a small value of Xc will result in an adhesive of high haze and low clarity. Unfortunately this 
increase in phase mixing is linked with a net reduction in the peel strength. Therefore, it can be concluded that as phase mixing within the microphase structure of the MCPU-U increases, the peel strength with PC or PC(t) decreases. It can be further concluded that surface treatment with an EA in IPA has no significant effect on the peel strength with this adhesive set. This conclusion is drawn from the comparable peel strengths obtained and consistent mode of failure observed regardless of PC interface.

\section{Acknowledgements}

The authors thank Dr P. L. Tang of Agilent Technologies for access to the infrared instrumentation and assistance with data processing. 


\section{References}

(1) Ewen J.C, K. In Advances in Structural Adhesive Bonding; Dillard, D. A., Ed.; Woodhead Publishing: 2010, p 3.

(2) Chattopadhyay, D. K.; Sreedhar, B.; Raju, K. V. S. N. Polymer 2006, 47, 3814.

(3) Chattopadhyay, D. K.; Prasad, P. S. R.; Sreedhar, B.; Raju, K. V. S. N. Progress in Organic Coatings 2005, 54, 296.

(4) Rahman, M. M.; Kim, H.-D.; Lee, W.-K. Journal of Adhesion Science and Technology 2009, 23, 177.

(5) Sánchez-Adsuar, M. S.; Papon, E.; Villenave, J. J. Journal of Applied Polymer Science 2000, 76, 1596.

(6) Cui, Y.; Chen, D.; Wang, X.; Tang, X. International Journal of Adhesion and Adhesives 2002, 22, 317.

(7) Gisselfält, K.; Helgee, B. Macromolecular Materials and Engineering 2003, 288, 265.

(8) Seymour, R. W.; Cooper, S. L. Macromolecules 1973, 6, 48.

(9) Li, W.; Ryan, A. J.; Meier, I. K. Macromolecules 2002, 35, 6306.

(10) Leibler, L. Macromolecules 1980, 13, 1602.

(11) Król, P. Progress in Materials Science 2007, 52, 915.

(12) Šebenik, U.; Krajnc, M. International Journal of Adhesion and Adhesives 2007, 27, 527.

(13) Petrović, Z. S.; Javni, I.; Divjaković, V. Journal of Polymer Science Part B: Polymer Physics 1998, 36, 221.

(14) Sanchez-Adsuar, M. S.; Martín-Martínez, J. M. Journal of Adhesion Science and Technology 1997, 11, 1077.

(15) Martin, D. J.; Meijs, G. F.; Gunatillake, P. A.; McCarthy, S. J.; Renwick, G. M. Journal of Applied Polymer Science 1997, 64, 803.

(16) Randall. D, L. S. The Polyurethanes Book Polymer Science and Technology, 2003.

(17) Neff, R.; Adedeji, A.; Macosko, C. W.; Ryan, A. J. Journal of Polymer Science Part B: Polymer Physics 1998, 36, 573.

(18) Shih, W.-C., Ou, T.-Y., Chung, C.-H., Weng, Y.-S. Journal of Technology, 2016, 31, 11 17 
(19) Yuan, Y., Zhang, Y., Fu, X., Jiang, L., Liu, Z., Hu, K., Wu, B., Lei, J., Zhou, C. RSC Advances 2016, 6, 83688-83696

(20) Li, C.; Wilkes, G. L. Journal of Inorganic and Organometallic Polymers, 1997, 7, 203.

(21) Painter, P. C.; Shenoy, S. L.; Bhagwagar, D. E.; Fishburn, J.; Coleman, M. M. Macromolecules 1991, 24, 5623.

(22) Petrovic, Z. S.; MacKnight, W. J.; Koningsveld, R.; Dusek, K. Macromolecules 1987, $20,1088$.

(23) Daniel-da-Silva, A. L.; Bordado, J. C. M.; Martín-Martínez, J. M. Journal of Applied Polymer Science 2008, 107, 700.

(24) Y1lgör, E.; Y1lgör, İ; Yurtsever, E. Polymer 2002, 43, 6551.

(25) Cakić, S. M.; Ristić, I. S.; Marinović-Cincović, M.; Špírková, M. International Journal of Adhesion and Adhesives 2013, 41, 132.

(26) Wen, T.-C.; Fang, J.-C.; Gopalan, A. Journal of Applied Polymer Science 2001, 82, 1462 .

(27) Yilgör, E.; Yurtsever, E.; Yilgör, I. Polymer 2002, 43, 6561.

(28) Elwell, M. J.; Ryan, A. J.; Grünbauer, H. J. M.; Van Lieshout, H. C. Polymer 1996, $37,1353$.

(29) Leitsch, E. K.; Heath, W. H.; Torkelson, J. M. International Journal of Adhesion and Adhesives 2016, 64, 1 .

(30) Li, Q.-A.; Sun, D.-C. Journal of Applied Polymer Science 2007, 105, 2516.

(31) García-Pacios, V.; Iwata, Y.; Colera, M.; Miguel Martín-Martínez, J. International Journal of Adhesion and Adhesives 2011, 31, 787. 


\section{Supplementary Data}

Nuclear magnetic resonance spectroscopy

All ${ }^{1} \mathrm{H}$ and ${ }^{13} \mathrm{C}$ nuclear magnetic resonance spectroscopy (NMR) experiments were carried out on a Bruker AVANCE 400 operating at a $400 \mathrm{MHz}{ }^{1} \mathrm{H}$ Larmor frequency and using a Bruker 5mm BBFO-Z broadband double-resonance probe. For both ${ }^{1} \mathrm{H}$ and ${ }^{13} \mathrm{C}$ solution state experiments, prepolymer sample solutions were prepared by dissolving the sample in an appropriate volume of dry deuterated-chloroform to yield a $50 \mathrm{mg} \mathrm{ml}^{-1}$ mixture. This mixture was left for 20 hours at $25^{\circ} \mathrm{C}$ to ensure complete dissolution of the prepolymer in the deuterated-chloroform before transfer to a $400 \mathrm{MHz}$ Norell ${ }^{\mathrm{TM}}$ 5mm NMR tube.

${ }^{1} \mathrm{H}$ spectra were obtained using a standard 1D sequence optimized for ${ }^{1} \mathrm{H}$ (Bruker ' $\mathrm{zg} 30$ ' pulse program). 16 scans for step-one prepolymers and 32 scans for step-two prepolymers were collected over a spectral window of $20 \mathrm{ppm}$. All ${ }^{1} \mathrm{H}$ spectra were referenced to deuterated-chloroform (solvent) singlet at $7.27 \mathrm{ppm}$. All ${ }^{13} \mathrm{C}$ spectra were obtained using a standard 1D sequence optimized for ${ }^{13} \mathrm{C}$ with ${ }^{1} \mathrm{H}$ decoupling at a $30^{\circ}$ flip angle (Bruker 'zgdc30' pulse program). 1024 scans for step-one prepolymers and 2048 scans for step-two prepolymers were collected with a spectral window of $220 \mathrm{ppm}$. All ${ }^{13} \mathrm{C}$ spectra were referenced to the deuterated-chloroform (solvent) triplet at $77.23 \mathrm{ppm}$.

\section{Matrix-assisted laser desorption ionisation time-of-flight mass spectrometry}

PU prepolymer samples were end capped with ethanol directly after synthesis to maintain molecular weight. Matrix-assisted laser desorption ionisation time-of-flight mass spectrometry (MALDI- ToF) was carried out on a Kratos Axima-CFR in linear mode using a time-of-flight mass spectrometer with a mass range of 1-150 kDa. The matrix solution was a mixture of $20 \mathrm{mg} \mathrm{ml}^{-1}$ in tetrahydrofuran of 2-(4-Hydroxyphenylazo)benzoic acid (HABA) and $1 \mathrm{mg} \mathrm{ml}^{-1}$ in water of sodiated trifluoroacetic acid (NaTFA). The matrix recipe was prepared from a 7:1 ratio of HABA to NaTFA. Prepolymer solutions of $40 \mathrm{mg} \mathrm{ml}^{-1}$ in tetrahydrofuran were prepared and mixed with the matrix recipe in an 8:1 ratio of matrix to sample. Two $0.1 \mu \mathrm{l}$ aliquots of the sample solution were spotted and the solvent was evaporated at room temperature prior to analysis. 


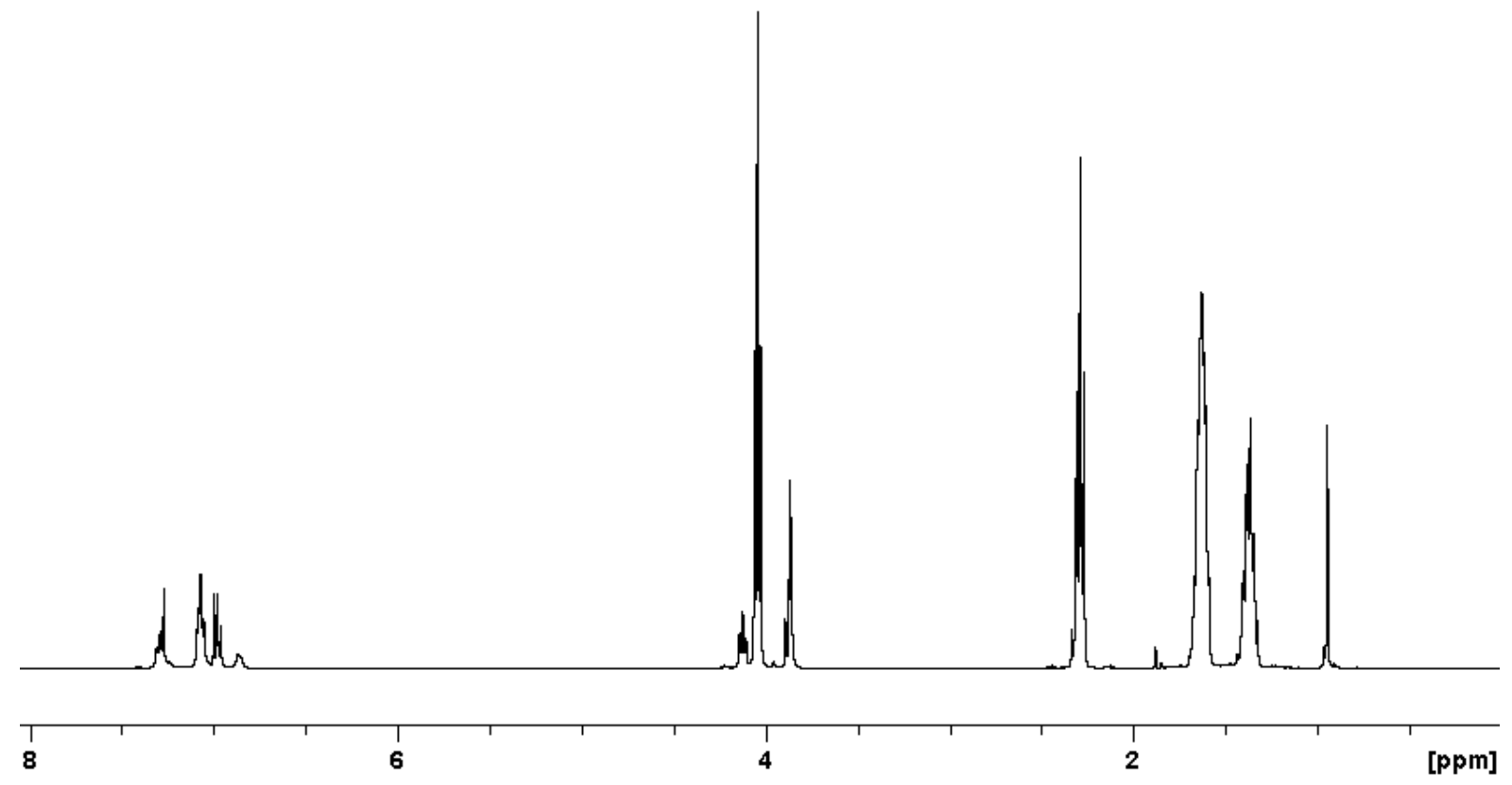

Figure SD1: ${ }^{1} \mathrm{H}$ NMR spectrum of MDI-TMP-PCD PU prepolymer in deuterated chloroform.

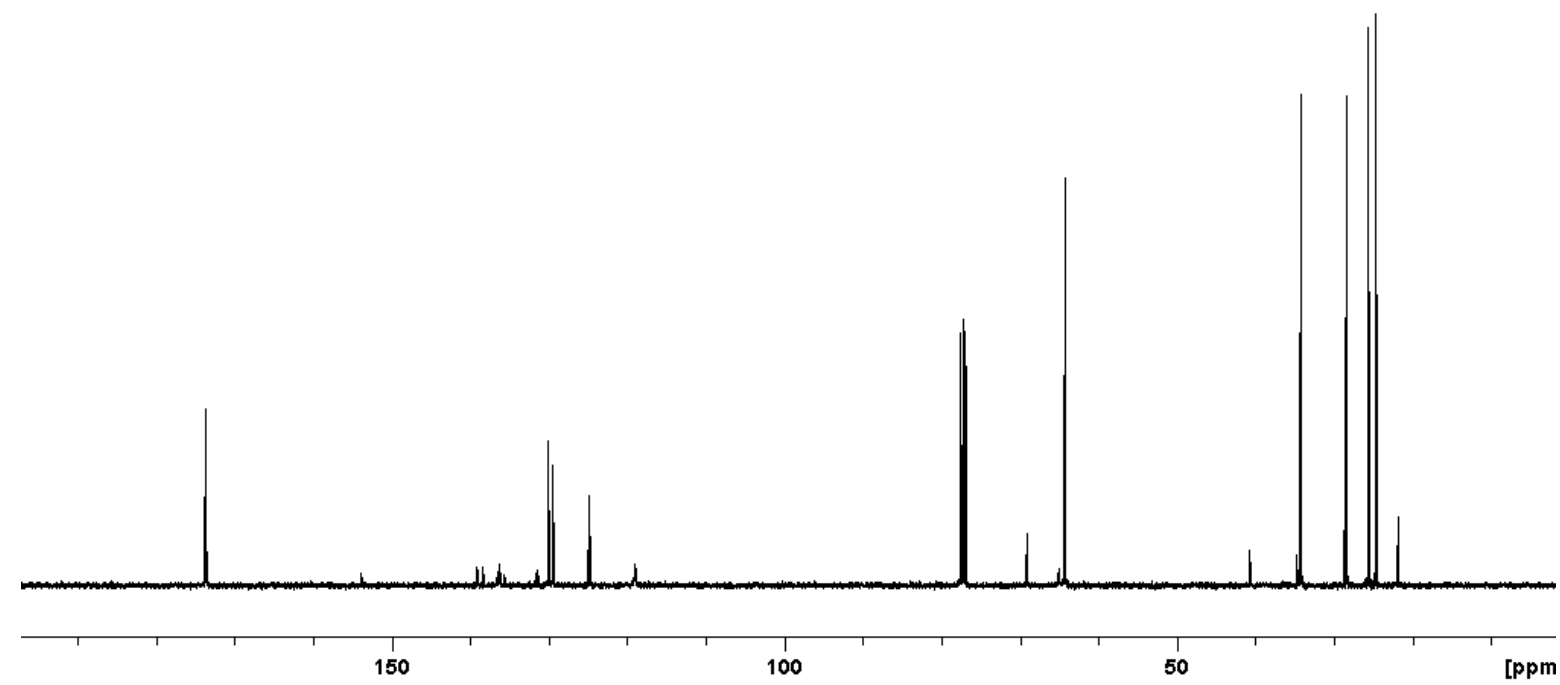

Figure SD2: ${ }^{13} \mathrm{C}$ NMR spectrum of MDI-TMP-PCD PU prepolymer in deuterated chloroform. 


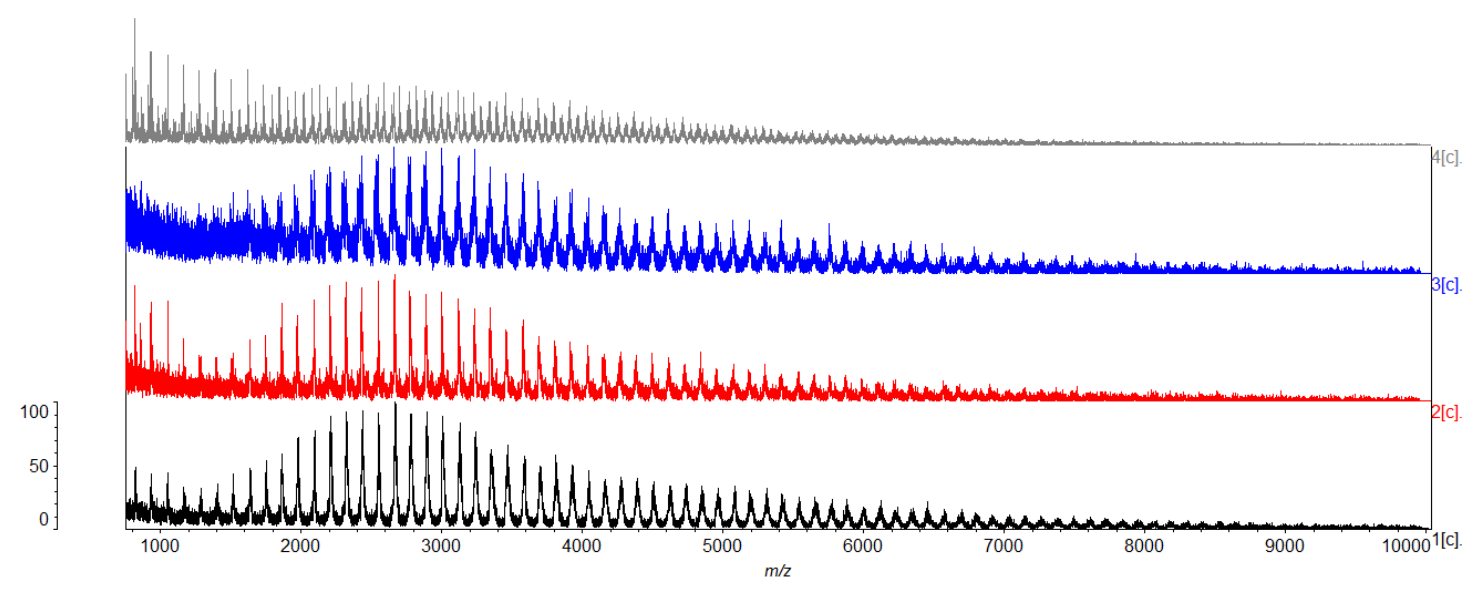

Figure SD3: Stacked MALI-ToF spectra of prepolymers based on MDI and PCD. MDI-TMP-PCD in black, MDI-TMP-PCD-DEPD in red, MDI-TMP-PCD-BD in blue and MDI-TMP-PCD-PD in grey. All prepolymer samples were ethanol terminated and analysed with matrix HABA/NaTFA.

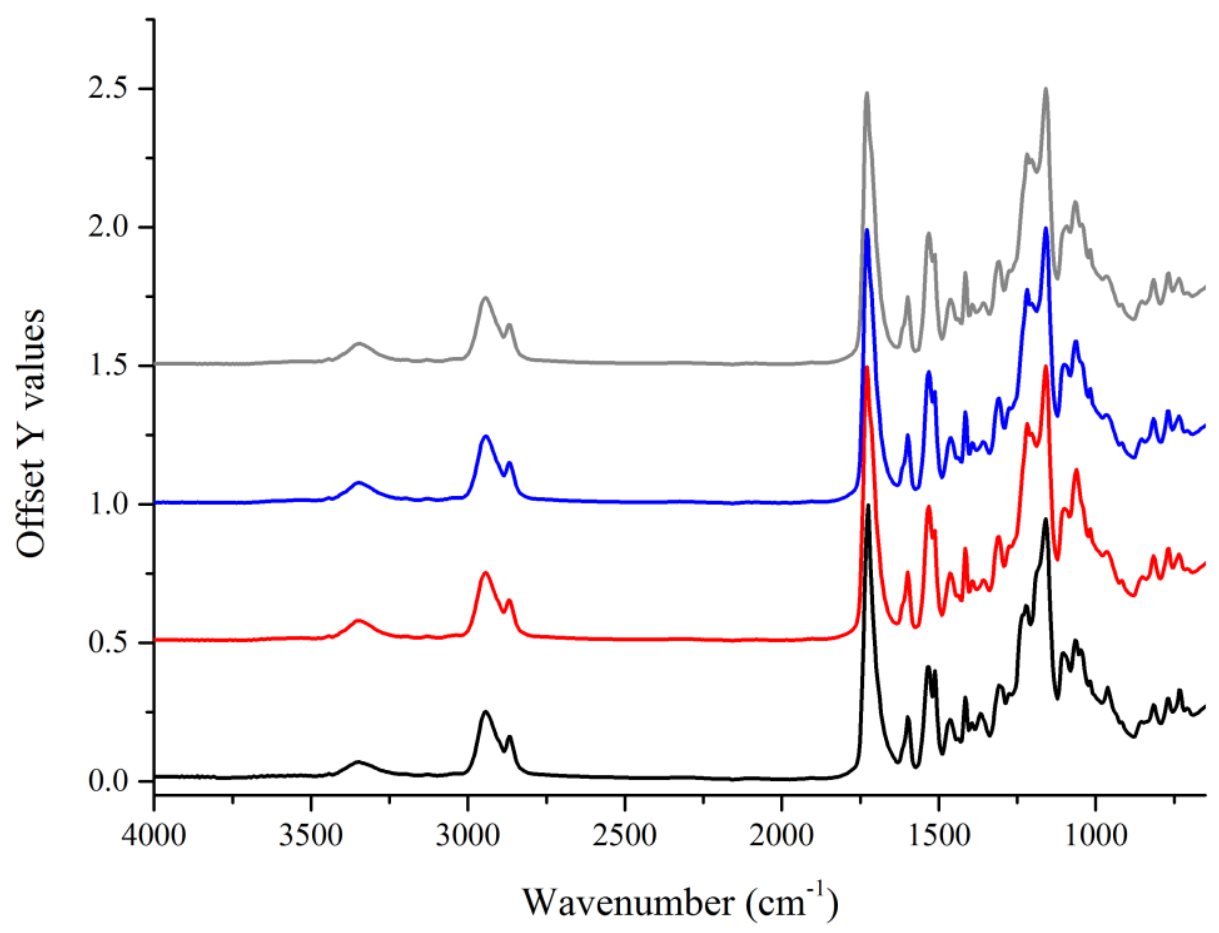

Figure SD4: ATR spectra of each MCPU-U adhesives based on MDI and PCD following 30 days of cure. MDI-TMP-PCD shown in black, MDI-TMP-PCD-DEPD shown in red, MDI-TMP-PCD-BD shown in blue and MDI-TMP-PCD-PD shown in grey. 
Prepolymer Analysis

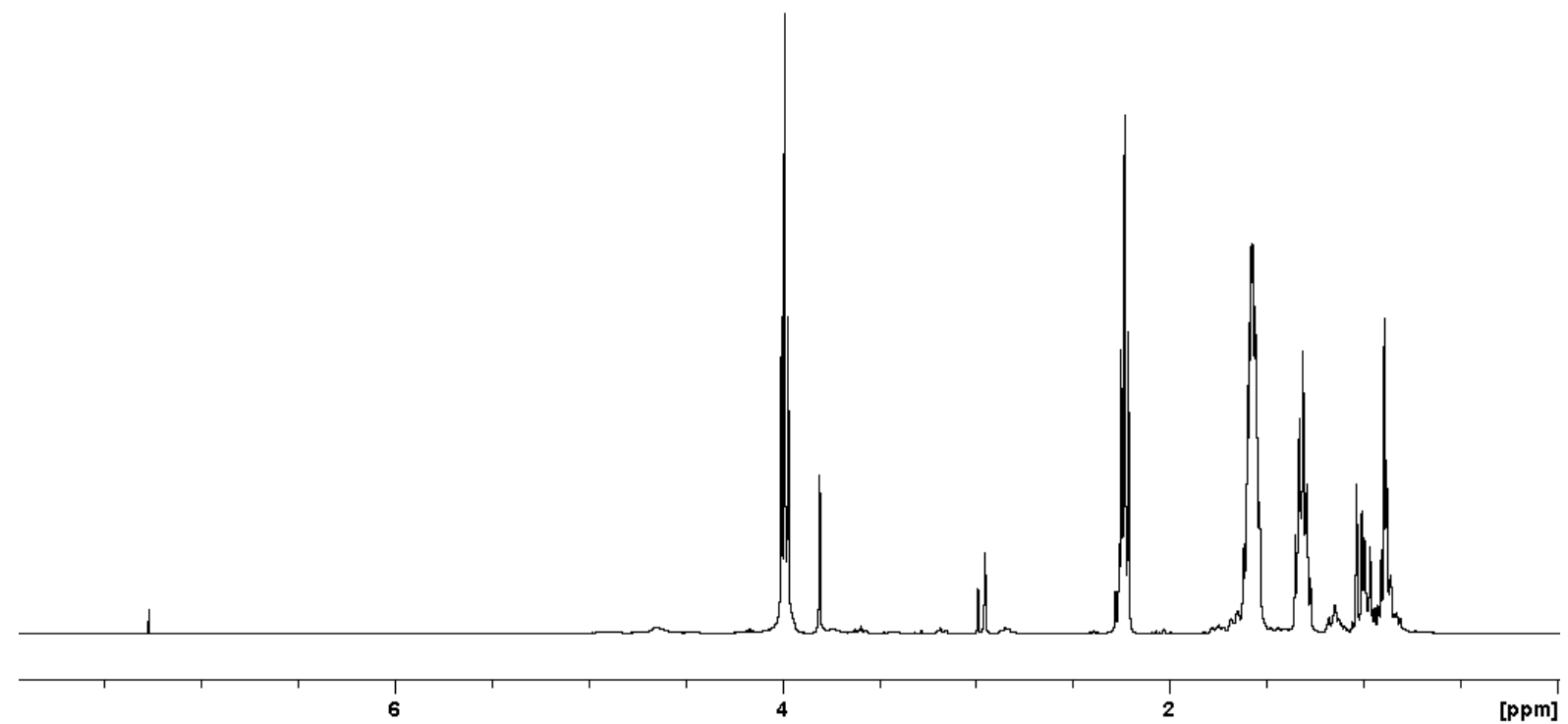

Figure SD5: ${ }^{1} \mathrm{H}$ NMR spectrum of IPDI-TMP-PCD PU prepolymer in deuterated chloroform.

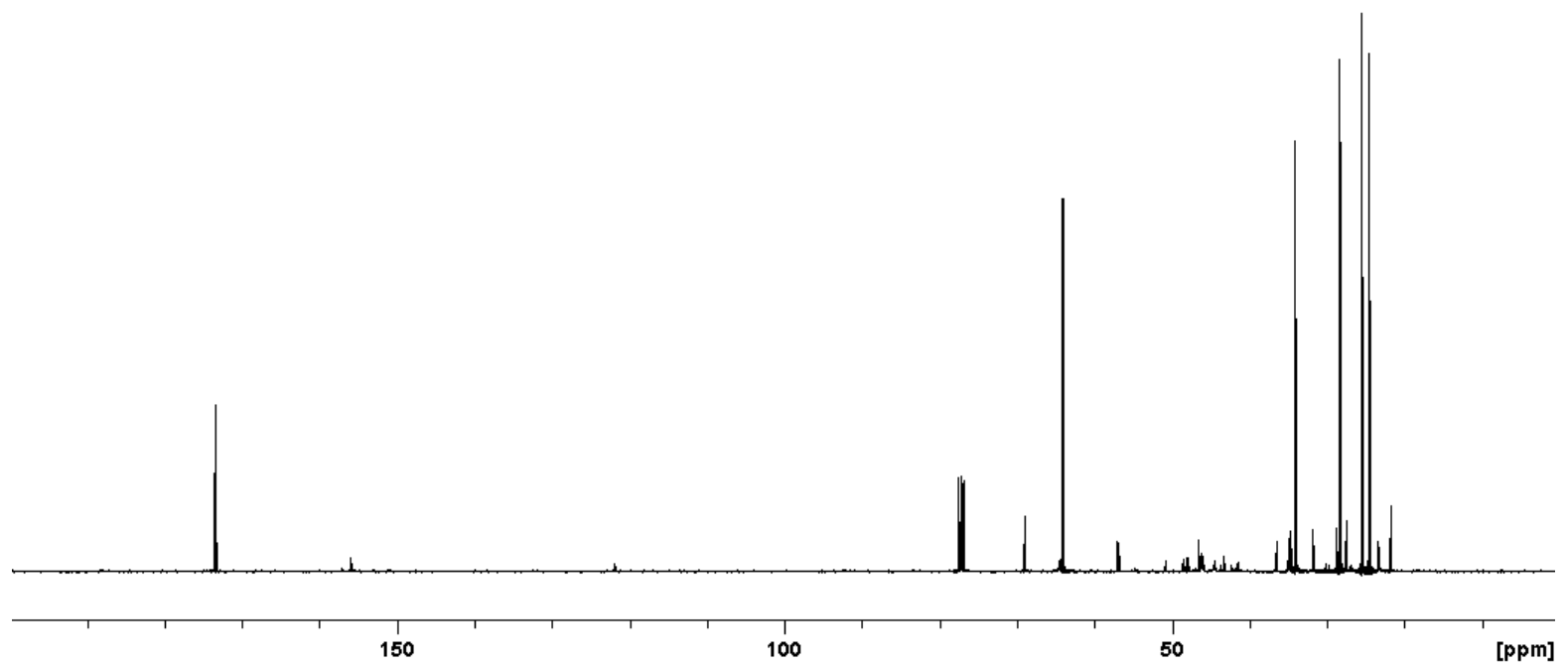

Figure SD6: ${ }^{13} \mathrm{C}$ NMR spectrum of IPDI-TMP-PCD PU prepolymer in deuterated chloroform. 


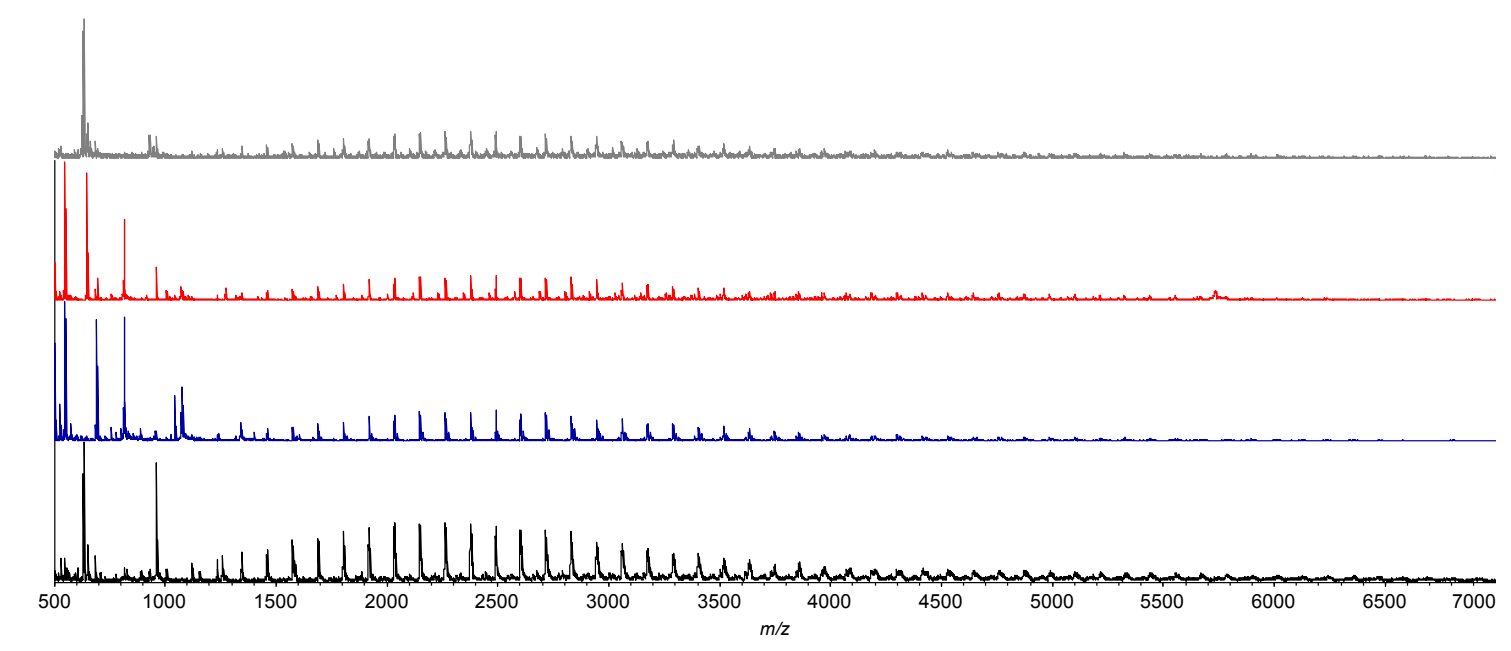

Figure SD7: Stacked MALDI-MS spectra of prepolymers based on IPDI and PCD. IPDI-TMP-PCD in black, IPDI-TMP-PCD-DEPD in red, IPDI-TMP-PCD-BD in blue and IPDI-TMP-PCD-PD in grey. All prepolymer samples were ethanol terminated and analysed with matrix HABA/NaTFA.

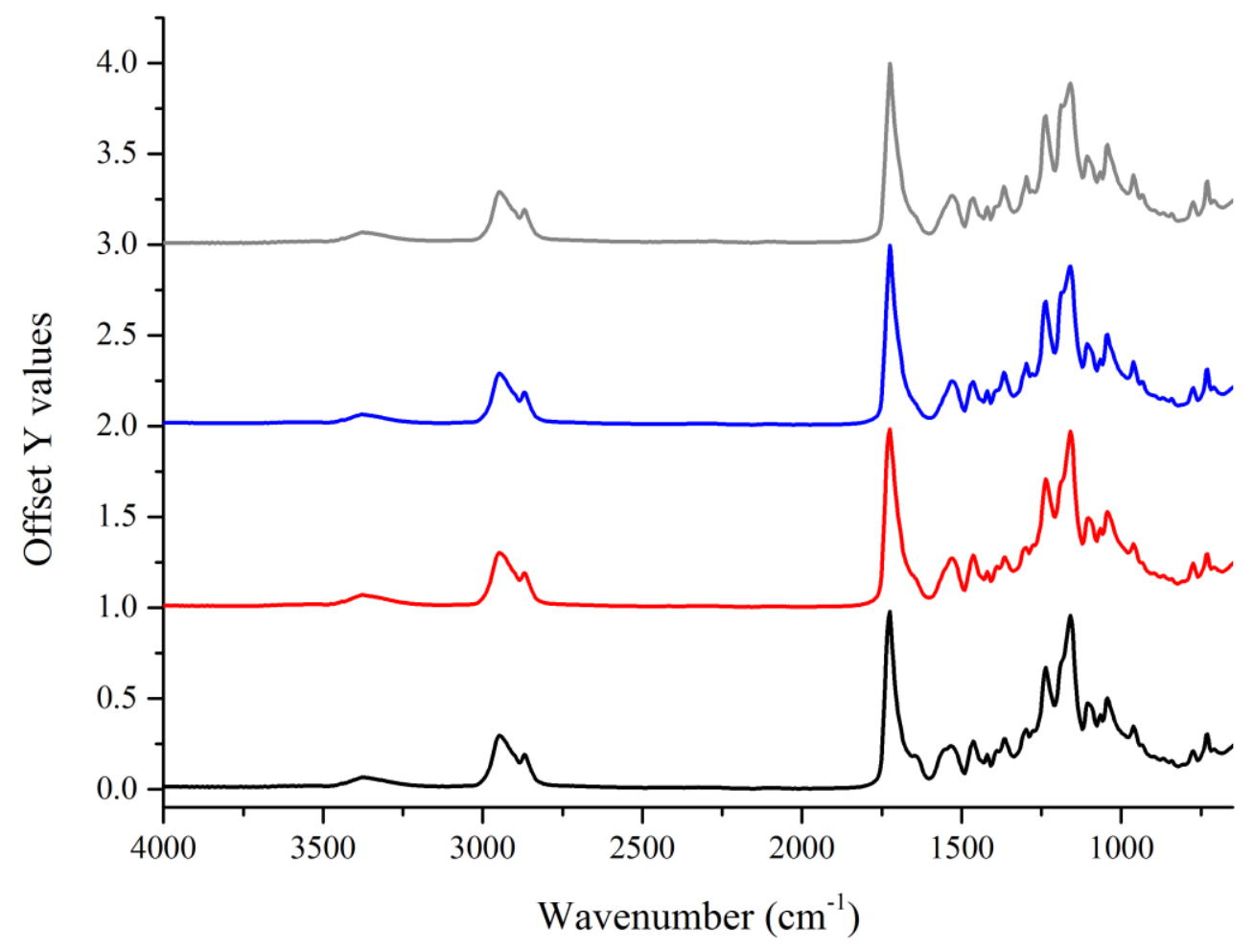

Figure SD8: ATR spectra of PU-U adhesives based on IPDI and PCD following 30 days of cure. IPDI-TMP-PCD shown in black, IPDI-TMP-PCD-DEPD shown in red, IPDITMP-PCD-BD shown in blue and IPDI-TMP-PCD-PD shown in grey. 